\title{
Mō tātou, ā, mō kā uri ā muri ake nei - For us and our children after us: \\ Iwi Entity in the Post-Settlement World
}

\author{
By
}

\section{Erin Renata Roxburgh}

A thesis submitted to the Victoria University of Wellington in fulfilment of the requirements for the degree of Masters of Commerce

Victoria University of Wellington

2016 
II P a g e 


\begin{abstract}
This thesis aims to gain a better understanding of iwi and their associated business entities in their post settlement phase and how they maintain their own kaupapa Māori.

The study examines the complex environment in which an iwi entity operates. This topic and environment has not been studied previously in academia and will therefore provide a unique insight from the study. The exploration was done through an in-depth analysis of a single organisational case study; the data collection method undertaken was in-depth interviews and document analysis.
\end{abstract}

The study found that the iwi entity has put specific strategies in place to ensure they maintained their kaupapa Māori. A focus was placed on how values and culture are transmitted through human resource practices of recruitment and induction. They did this through formal mechanisms, such as documentation and training, as well as informal mechanisms such as socialisation, history, and oral story telling. What was most unique as a finding was that traditional iwi values and methods were brought through into the contemporary business setting at the iwi entity.

Contributions from this study are made to the Māori business and Māori management literature, as well as Strategic Human Resource Management literature and organisational culture literature. In a practical sense there are implications for Māori organisations, iwi entities and non-Māori organisations. 


\section{Acknowledgements}

I cannot express the amount of gratitude I have for those who helped me through this journey. Although this is my work, everyone mentioned here made a small contribution to this study. Whether it was offering support, being a sounding board for my ideas or even if it was just to take me out for a coffee when I needed a break. Thank you to all of you.

Firstly, thank you to my supervisor, Sarah Proctor-Thomson. Thank you for taking a chance and for stepping into the unknown with me. I could not have done this without your feedback on my theoretical aspects and practical aspects of my study. You always pushed me that extra mile, and made my work the best it could be.

Secondly, thank you to Ngāi Tahu for allowing me to study your mahi. This was an opportunity for which I will be forever grateful. Thank you for opening your home to me and for allowing me to gain insight into your kaupapa. It is an experience that inspired me and allowed my adventure into the nature of an iwi.

To my 'Disasters from Masters', thank you for your friendship. Over our Honours and Masters years we have suffered, celebrated and grown together through our shared experience. Without your continued friendship, I wouldn't have been able to get through this process.

Thank you to my friends. I would not have could get this far without the amazing friendships I have in my life. Thank you to these people for picking me up and helping me to keep moving forward.

Lastly, thank you to my Whānau. Words simply will never be able to fully express the gratitude I have for you. Thank you for supporting me, having confidence in me and for being my inspiration. To my Nanny Tua, you aren't with us anymore, but your presence continues to push me forward, and inspire me. Lastly, I would like to acknowledge my tāne, William. You have supported me, and been my rock through every part of this journey. You have built this dream with me. 


\section{Table of Contents}

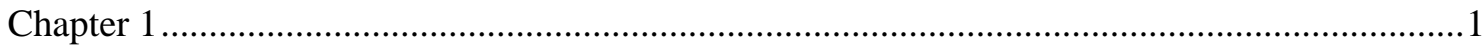

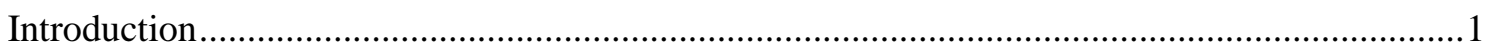

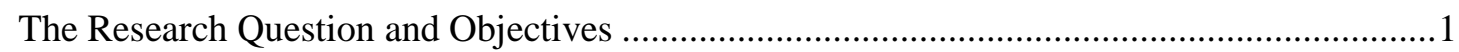

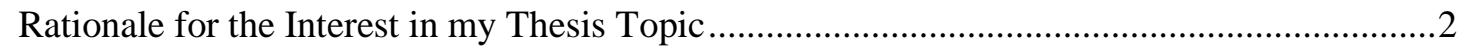

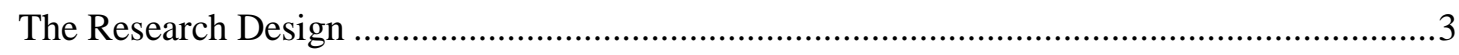

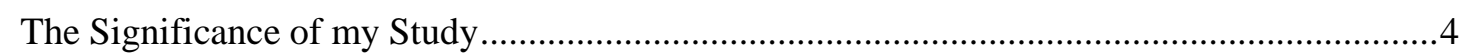

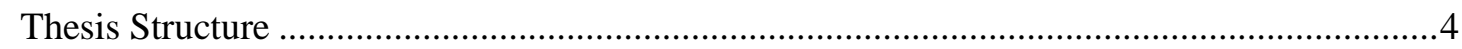

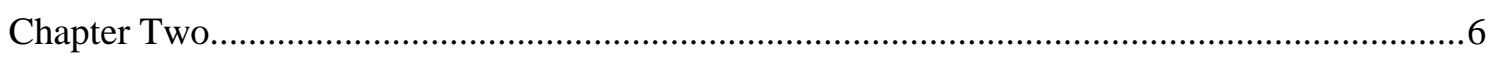

History and Context: Te Tiriti o Waitangi, Settlements and the Settlement Process....................6

Post-settlement World for Iwi ....................................................................................... 10

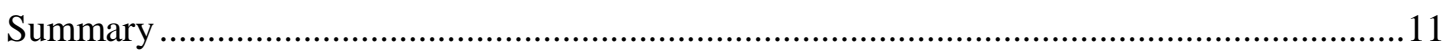

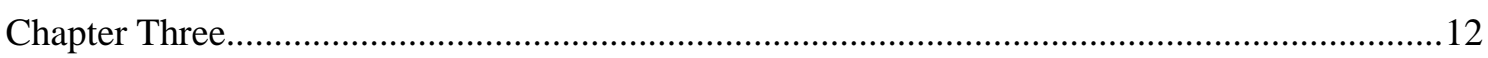

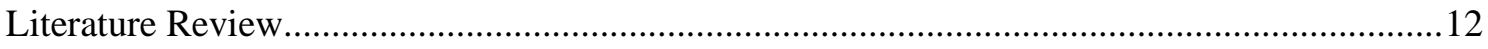

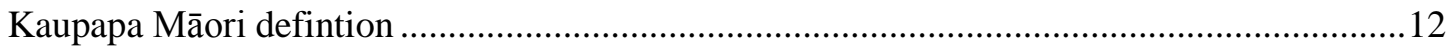

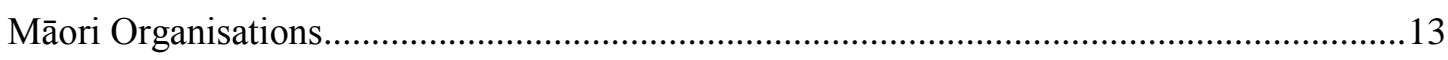

Māori Values and Their Relationship with Business ...............................................................14

The Role of Strategic Human Resource Management ...........................................................15

Organisational Behaviour - a Māori perspective ...................... Error! Bookmark not defined.

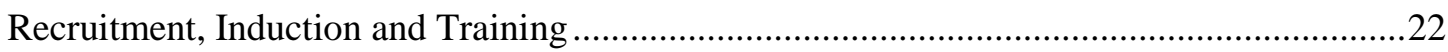

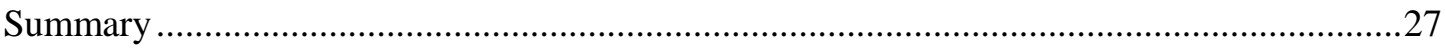

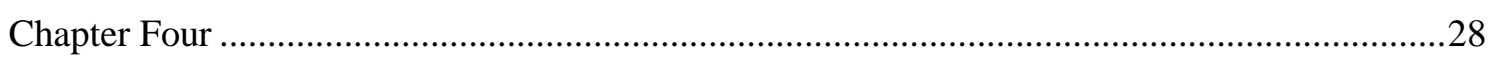

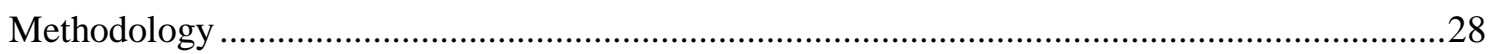

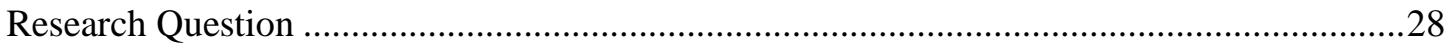

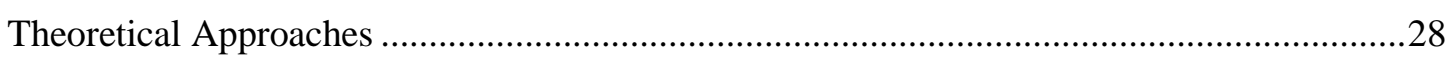

The Kaupapa Māori Research Approach ...........................................................................30

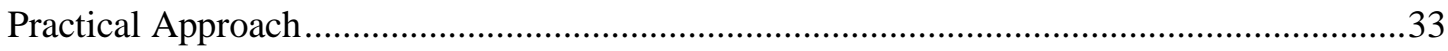

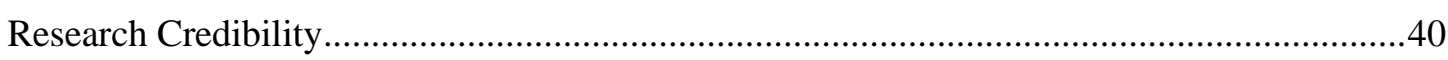

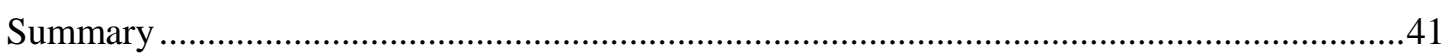

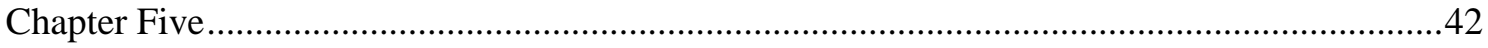

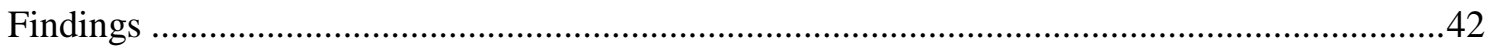

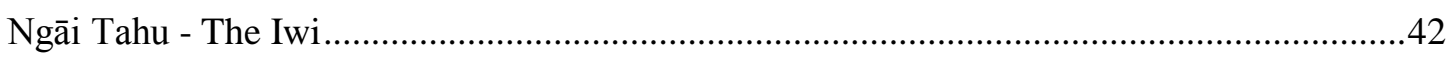

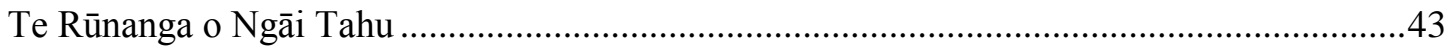

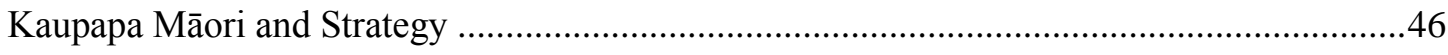

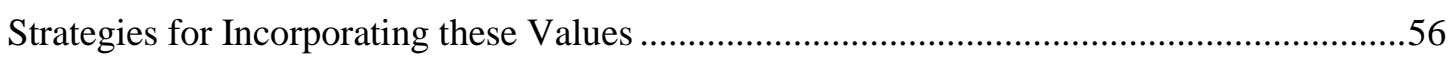

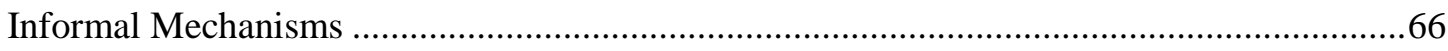

Summary

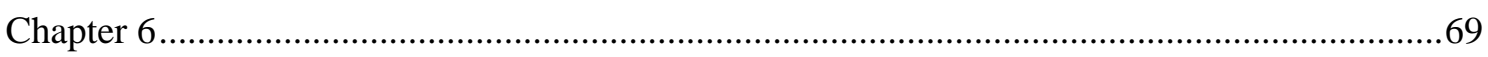

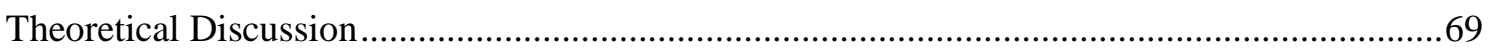


Tikanga Māori and Values

69

Kaupapa Māori as a Strategic Framework Error! Bookmark not defined.

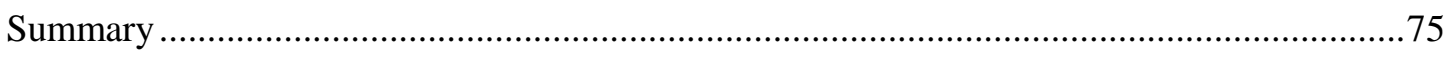

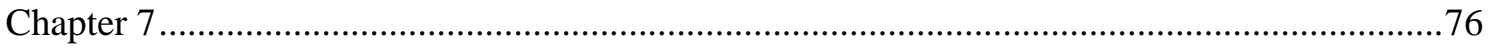

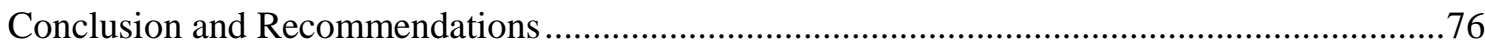

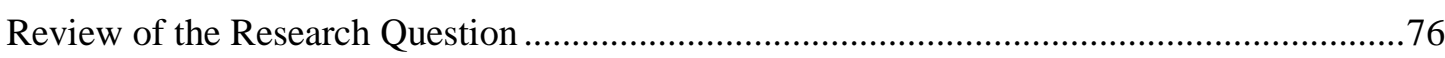

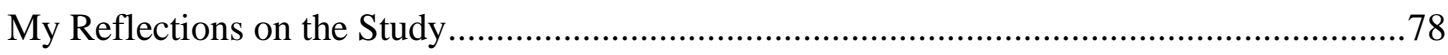

Recommendations for Future Research ………..................................................................

The Contribution of my research to Human Resource Management Literature and

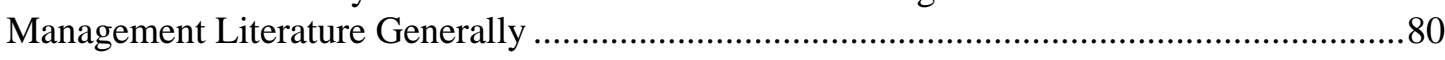

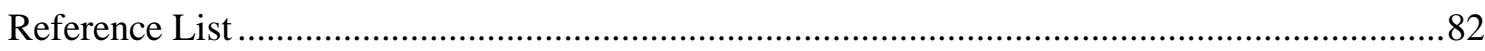

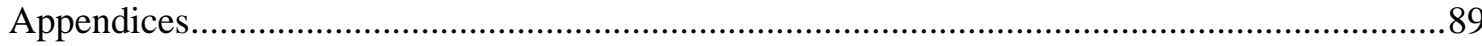

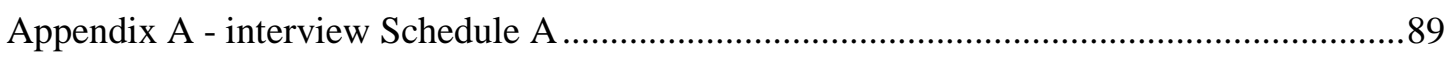

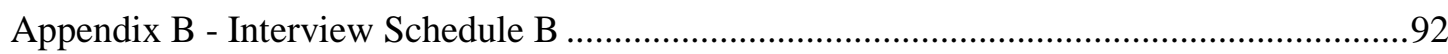

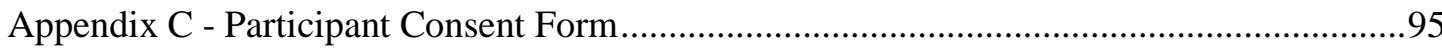

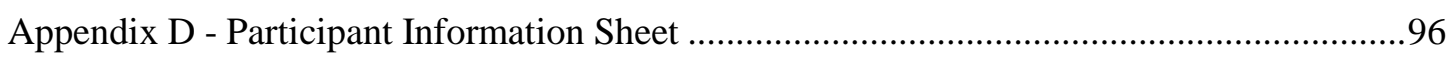




\section{Chapter One \\ Introduction}

This thesis aims to gain a better understanding of iwi and their associated business entities in their post-settlement phase and how they maintain kaupapa Māori. It does so by examining specifically the recruitment, training, and induction processes within a case study organisation - Ngāi Tahu Holdings (NTH). Information was collected through interviews with ten senior managers within the case study organisation. The exploration included the managers' own experiences of recruitment, training, and induction and how they managed these processes for others. The managers were also asked about their strategies for managing these Human Resource Functions. The participants were also asked to describe what they saw as challenges of maintaining kaupapa Māori in their organisation.

With iwi entities now operating in business, areas of conflict can arise. For example, iwi may face pressure to compromise their values and identity in order to be commercially successful. I explore this conflict, and look at how iwi entities deal with the conflict by considering the strategies that are used to preserve their culture.

The purpose of this chapter is to provide an overview for the study. I will firstly introduce the core research question, sub-questions, and objectives. I will then describe the rationale for my personal interest in this topic and subject area. The contribution of the study will be discussed and the thesis structure outlined.

\section{The Research Question and Objectives}

The following research question guided my research:

How does an iwi entity preserve their kaupapa Māori (integrity to traditional values) through their māhi (work) whilst operating in a Western business context? 
This research question was developed in order to collect in-depth information for a better understanding or to gain knowledge on how kaupapa Māori is protected within organisations through their recruitment, training, and induction processes.

In order to answer the research question, the following research objectives were established:

1) To understand what processes are put in place through recruitment, training, and induction to protect kaupapa Māori in the organisation

2) To find out what is defined as a 'best-fit' candidate in an iwi entity and how this affects their recruitment choices

3) To examine the organisations strategic approach and its relationship with kaupapa Māori

4) To investigate what further challenges lie ahead for iwi entities in protecting their kaupapa Māori, through the managers' experiences within the iwi.

\section{Rationale for the interest in my thesis topic}

My rationale for investigating this thesis topic derives from a personal and academic point of view. Firstly, from a personal perspective - I am Māori. I am of Ngati Porou and Nga Puhi descent. I have always felt a strong connection with my culture and my people, and this led me to an interest in exploring the operations of Māori businesses, and more specifically, iwi entities. This study is also directly linked to the career I hope to pursue working for iwi. Secondly, from an academic perspective there is limited literature on Māori in business, therefore I am inspired to contribute to this.

Throughout my post-graduate career, I have endeavoured to frame my work around Māori business and have been strongly motivated to contribute to this area. I believe traditional Māori values and te ao Māori (Māori world view) have much to offer Western business and I want to be able to raise awareness of these intrinsic Māori values.

Moreover, it was my attendance at a seminar held at university with iwi business leaders that inspired my interest in delving deeper into iwi business. I was captivated by this particular presentation as the iwi leaders explained the conflict they face with trying to operate successfully in a western business environment and at the same time maintaining 
their kaupapa Māori and upholding cultural integrity. The iwi leaders explained that they had endeavoured to implement policies to ensure kaupapa Māori and cultural integrity was maintained.

I decided to conduct my case study on a well-established iwi entity that was open to engagement with me on this topic. The decision to research this topic has reinforced my interest in the use of Māori values in business and has also forced me to research further into Te Tiriti o Waitangi (The Treaty of Waitangi) and the complexities of settlement for iwi. Learning about this has been an invaluable experience and has expanded the way I think about iwi entities. I hope to shed light on the experiences of these iwi and to give a voice to the positive work they are doing in creating their own Māori way of being in business.

\section{The Research Design}

The data for this case study were obtained from one case study organisation with a total of ten managers interviewed. The participants all work in senior management roles within the organisation, including some who work in HR within the organisation. The interviews were conducted to gain a thorough understanding on the recruitment, training and induction methods used within the organisation to protect and maintain kaupapa Māori as the iwi enters its post-settlement phase.

Other complementary data were collected through the analysis of documents provided by the case study organisation.

The study does not attempt to make any changes in the performance of the firm but rather to understand and describe the examined processes. This is to benefit the iwi itself and also to benefit other iwi entities as they move through their own post-settlement phase. I personally selected and approached the organisation, and they ultimately consented to be interviewed and studied.

The 'kanohi ki te kanohi' (face-to-face) method was integral to my study. An important value in Māori society is that people meet face-to-face so that trust and the relationship can be further developed (Pipi, 2004). Kanohi ki te kanohi is regarded within Māori communities as critical when one has an important task or purpose. This form of 
consultation allows the people to use all their senses as complementary sources of information for assessing and evaluating the advantages and disadvantages (Pipi, 2004). In being able to conduct face-to-face interviews, I was able to maintain integrity with my work approach.

Prior to the actual process of data gathering, a smaller pilot study was undertaken and this helped to refine and better form my data collection tools for the actual study. The qualitative data from the participants interviewed and organisational documents gathered were analysed using thematic analysis through the exploration of repeated words, phrases, concepts, and the interconnectedness of themes. The full description of research strategies is provided in Chapter Three of this thesis.

\section{The Significance of my Study}

In summary, I am interested in this topic area as I am myself Māori, and am particularly interested in Māori business and its use of traditional Māori values. I seek to provide a thesis that sheds light into the challenges that exist for Māori in the modern New Zealand business environment, and which process enable iwi entities to navigate these challenges. My personal aspiration is to develop research that will assist Māori and contribute to society through broadening the way that iwi and settlements are viewed. My observation is that there are often negative connotations surrounding Te Tiriti o Waitangi settlements and the investment decisions that iwi have undertaken previously. This study aims to provide balance to this argument.

\section{Thesis Structure}

The thesis comprises seven chapters, including this introductory chapter. Chapter Two presents a history and context of Te Tiriti o Waitangi, the settlement process, and postsettlement government entities. This chapter is crucial to provide context for the case study.

Chapter Three presents a review of the literature relevant to the research. Chapter Four describes details of research strategies involved in the current study. These two chapters present the core research question and sub-questions that were used to guide the research process, and discuss the research paradigm, methodology, and data collection methods. 
The section on research methods provides an explanation of how the organisation and participants were selected and the tools used for gathering and analysing data.

Chapter Five presents the findings from the case study. Chapter Six further develops the analysis of the themes that emerged from the case study and links the findings to the theoretical models and broader literature presented in Chapter Two. Chapter Seven concludes this thesis with an overall review of the research question and sub-questions in response to my findings. It provides reflections on the current study and provides recommendations for further research and action. 


\section{Chapter Two \\ Te Tiriti o Waitangi, Settlements, and the Settlement Process}

The signing of the Treaty of Waitangi in 1840 was a significant event, the lives of Māori and Pākehā. This section of the literature review will provide history and context as to why Te Tiriti o Waitangi was originally signed, what was agreed, and the past and present implications for New Zealand.

On the $6^{\text {th }}$ of February 1840, rangatira (tribal leaders) and the Queen's representatives signed Te Tiriti o Waitangi (Wheen and Hayward, 2012). It had always been clear to Māori that the Treaty recorded conditions under which Pākehā could remain in the country they called New Zealand (Wheen and Hayward, 2012). By signing this Treaty, the Queen had agreed to the wishes of the Rangatira of Te Whakaminenga o ngā Hapū, those rangatira whom her father, the King, had acknowledged held sovereignty over their territories in this country (Wheen and Hayward, 2012). The rangatira had asked the King to take control of his lawless subjects residing in this land, to educate them, and to teach them about the mana (power) and rangatiratanga (sovereignty) of the hapū on whose lands they were living. It was thought this would allow Māori and Pākehā to live in peace (Wheen and Hayward, 2012).

However, this was not the case. Professor Mutu (2010) discusses the issues that arose out of the misinterpretation of Te Tiriti o Waitangi. Professor Mutu (2010) closely examines the English and Māori versions of the Treaty and highlights the key issues surrounding each Article. The main arguments posed that have been significantly mistranslated are to do with the interchanging use of kawanatanga (governance) and rangatiratanga (sovereignty) throughout Article Two of the Treaty.

The word kawanatanga and its use is a particularly relevant issue. Mutu (2010) brings to light the fact that the word kawanatanga, meaning governorship, is in fact a borrowed word from English and does not hold the same weighting or meaning in Māori as it does in English. This is borne out through the translation of Article Two in both English and Māori versions where in fact Māori ceded sovereignty through signing Article Two in which the word kawanatanga was inappropriately used. Perhaps a better word to have used here would have been rangatiratanga. The word rangatiratanga does not hold the same meaning or uphold the same weighting in English as it does in Māori. Therefore, 
there was an apprehension by the English to use this word in fear that Māori would not sign the Treaty.

The Treaty did not however serve the purpose for which it was intended, after becoming lost in the New Zealand judicial system. In the 1877 Wi Parata case itself (Wi Parata $v$ Bishop of Wellington, 1877), which involved Māori land at Porirua, Judge Prendergast ruled that the courts lacked the ability to consider claims based on aboriginal or native title. He described Te Tiriti o Waitangi as 'worthless' because it had been signed 'between a civilised nation and a group of savages'. In his view, the Treaty had no judicial or constitutional status because Māori were not organised into a nation capable of signing a treaty. Since the Treaty had not been incorporated into domestic law, it was considered a "simple nullity" (Ministry for Culture and Heritage, 2015).

This case proved significant, and during the period 1840 to 1975 Te Tiriti o Waitangi has been referred to by Tama Potaka (2012) as 'lost at sea'. Potaka (2012) describes this period as a time where the Treaty was completely absent from legislation. The key assumptions underlying its exclusion are not entirely clear, other than the fact that the Treaty was considered a "simple nullity" by lawmakers. Through this period, Te Tiriti o Waitangi was not considered by the Government when making other legislation. The original purpose of the Treaty has been to provide a document that protected both Māori interests and those of the Crown. However, it did not serve its purpose; throughout this period legislation was made that directly contradicted the Treaty.

The enactment of the Treaty of Waitangi Act (1975) dramatically changed the course of the Treaty and its role into legislation (Potaka, 2012). The second era, dubbed "the tide turns" by Potaka (2012) covers the period 1976 to 1999, where New Zealand saw an explosion of legislative activity in regards to the Treaty (Potaka, 2012). This coincided with a heightened political action which led to legislative, administrative, and judicial changes regarding the Treaty. The Treaty of Waitangi Act 1975 is regarded as the catalyst for this action (Potaka, 2012).

The Treaty of Waitangi Act 1975 established the Waitangi Tribunal (the Tribunal) and gave Te Tiriti o Waitangi recognition in New Zealand law for the first time (Potaka, 2012). The Tribunal was empowered to investigate possible breaches of the Treaty by the 
New Zealand government or any state-controlled body, occurring after 1975. This led to a review of the appropriate interpretations of the Treaty clauses in legislation, where there was further awareness of critical Treaty issues requiring legislative responsiveness. As a consequence of these actions there was also a public renaissance of all things Māori, in terms of educational and cultural re-invigoration (Hayward, 2014).

Since this period, the Crown has engaged in negotiations aimed to settle Māori historical grievances against the Crown (Hayward, 2014). These grievances date back as far as 1840, and involve or have involved many hapū (family groups), and iwi across most of the country. Wheen \& Hayward (2012) define settlements as "agreements between the Crown and the Māori claimant groups that, as Crown policy states, settle claimant groups", or historical claims against the Crown. The settlement process itself is entirely in Crown control which has led to discussion about inequity in bargaining power in the negotiation process for Māori.

The settlement process is administered by the Office of Treaty Settlements, which operates separately as a part of the Ministry of Justice (Cowie, 2012). The aim of the settlement process is to provide a foundation for a new Crown-Māori relationship going forward (Cowie, 2012). Often settlement claims will include apologies of wrong doings by the Crown. There are three stages to the settlement process: pre-negotiation, negotiation, and implementation (Cowie, 2012). As at 2011, 34 deeds had been signed, with the government's aim to have all major claims by largely settled by 2016 (Cowie, 2012).

Vertongen (2010) discusses the Treaty settlement process as evolving from the first settlements and as one that has turned into a relatively standardised process through which settlements are produced. Despite the standardised nature of this process, Treaty settlement negotiations often contain significant conflict and dispute, ultimately being subject to a range of legal disputes from various parties (Vertongen, 2010). The nature through which these disputes arise varies. There are mandate disputes, which bring into focus the inconsistency between the legal basis for making a claim and the Crown's policy for negotiating only with large groups, overlapping claim challenges; disputes arise over other groups also claiming to hold interest in particular assets. Vertongen (2010) notes 
also that challenges to the process and this framework have on-going implications into the way negotiations are undertaken (Vertongen, 2010).

The concluding argument made is that because the settlement process has no statutory framework through which decisions are made, and because outcomes are implemented through a passing of legislation through parliament, courts are reluctant to intervene in the settlement process no matter how compelling the argument (Belgrave, 2010). There is also a distinct lack of policy concerning the needs and interests of settled claimant groups which need to be addressed (Belgrave, 2010).

Joseph (2012) explores the complexity of Māori and tribal communities and notes that these are complex environments. The issue is that from the Crown's perspective there is a blanket definition of identity, eligibility, and mandate about Māori and tribal communities within the settlement process. It is identified that on the whole the Crown procedures and policies do not accommodate Māori individual, whānau, and small hapū claims due to the Crown policy of preferring to deal with 'large groupings'.

After the Waitangi Tribunal was first established in 1975, the Labour Government then passed legislation in 1984 to afford the Tribunal retrospective powers to investigate claims that date back to 1840 . The Tribunal can make non-binding recommendations to the Crown as to what it believes to be valid claims. Although claimants do not have to go through the Tribunal in the claim process, it is of value to do so. The work of the Tribunal in reclaiming settlements for iwi and hapū has been instrumental. Ruru (2010) suggests that the Tribunal is a symbol of biculturalism by appointing both Māori and Pākehā members who are comfortable in both environments.

The Tribunal adopted an interpretive method for the Treaty-based principles and was prepared to acknowledge the English and Māori interpretations of the text (Potaka, 2012). For example, taonga (treasure) in the Māori language could be interpreted as both tangible treasures (such as natural resources) and intangible treasures (such as independence and sovereignty). Most importantly, Potaka (2012) notes that the Tribunal highlighted the Treaty as being a partnership and a gift of kawanatanga in return for a promise to protect rangatiratanga. The nature of this exchange continues to be at the forefront of Treaty constitutional discourse. 
The Waitangi Tribunal has been paramount in ensuring that the Treaty is no longer regarded as a 'simple nullity' in the New Zealand legislative system. By 1998 the Tribunal classified the Treaty as New Zealand's "basic constitutional document” (Ruru,2010). In 2001, Ruru (2010) also notes that the Napier Hospital Tribunal stated that Te Tiriti o Waitangi is the foundation document for a modern New Zealand constitution. Full progress has not been made, however, with the New Zealand parliament still yet to determine whether the Treaty and its meaning are specifically included in legislation, or are still in effect only de facto.

\section{Post-Settlement World for Iwi}

Previously the review has looked at the establishment of the Treaty in our constitution. We are now in a period where the future looks uncertain for the post-settlement world. Potaka (2012) describes this era as "uncharted waters" covering the period 1999-2010, where parliament is seeking to better define the legislative meaning of the Treaty and its role in our constitution.

Bargh (2012) examines the issues surrounding some of the Crown settlement on Māori and their implications. The most notable argument made is that Māori have quite different expectations from the Crown, in terms of what settlements should deliver. Māori are guided by the Declaration of Independence (1835) and Te Tiriti o Waitangi in seeking greater control over Māori resources. The Crown on the other hand looks to focus its attention on acknowledging historical breaches and looking to improve social and political conditions for Māori through economic development.

Chen (2015) states that we now see Māori in control of 37\% of New Zealand's total fish quota, 36\% of New Zealand's forests, and points out that iwi are investing in telecommunications, infrastructure, property and, tourism. Chen (2015) also asks the question: "How do we future proof our taniwha economy for future generations?", that is: what are we currently doing in the present to assist the future of our people in these areas? 
Kukutai (2015) argues that iwi organisations are New Zealand's biggest untapped resource. As iwi move from a grievance model to a development model. It means in a business sense, iwi need to have a robust and transparent distribution model in allocating resources post-settlement. Kukutai (2015) states that iwi need a governance model in the post-settlement era that represents the interests of the collective also.

\section{Summary}

By providing a discussion of Te Tiriti o Waitangi and the settlement process, there is now a foundation upon which to set this thesis. The past few decades have seen iwi mobilise into organisations after their settlements is over, and look to use capital from settlements to reinvest into their people and futures. The next chapter will lead a discussion and review of the literature on this topic. 


\section{Chapter Three}

Literature Review

\section{He aha te mea nui o te ao? He tāngata! He tāngata! He tāngata!}

What is the most important thing in the world? It is people! It is people! It is people!

To provide context for the original research component of this thesis, I present in this chapter a review of the existing literature exploring the nature of Māori organisations, and explain widely shared traditional Māori values. The existing literature is relatively small, but helps to identify areas for further research. The concept of Strategic Human Resource Management (SHRM) will be defined and introduced with regard to values, vision, and leadership, and how strategically aligning this within recruitment, training, and induction is imperative to an organisation's success. It will finally make the argument that maintaining kaupapa is crucial to Māori organisations.

The chapter will begin by discussing Māori organisations, including their common formation and linkages with history. It will discuss the importance of a sense of cultural belonging for Māori and the implementation of Māori values in organisational strategy.

Overall, this review will present an overview of existing research in the key topic areas: Māori organisations and their formation, strategic HRM, recruitment, training, and induction, in order to form a sound basis for the rest of my study.

\section{Kaupapa Māori definition}

It is important to acknowledge that the basis of the key research question uses the term 'kaupapa Māori'. Through using this phrase, I also acknowledge that there are multiple and subjective definitions to this phrase, there are also differing ways that it is used. I will provide a summary of definitions from the literature to define precisely what I mean by this term moving forward.

Kaupapa Māori has been described as the embodiment of living a Māori culturally informed life that takes for granted the legitimacy and ownership of Māori knowledge and practice (Ruwhiu, 2016). Henry and Pene (2001) define kaupapa Māori, as literally an agenda or Māori way of doing things. They point out that it is a term used to describe 
traditional Māori ways of doing, being, and thinking, encapsulated in a Māori world view or cosmology (Henry \& Pene, 2001).

With these definitions in mind, I will be using the phrase 'kaupapa Māori' in this to refer to a Māori way of doing things. In doing this, as per the definitions above, this encapsulates Māori knowledge, practice and thinking in the way one operates.

Henry and Pene (2001) argue that kaupapa Māori is both a set of philosophical beliefs and a set of social practices (tikanga). They also note that these are founded on the collective (whanaungatanga) interdependence between and among human kind (kotahitanga), a sacred relationship the 'gods' (waitangirua), and an acknowledgement that humans are guardians of the environment (kaitiakitanga). These beliefs are combined in the interconnection between mind, body, and spirit (Henry \& Pene, 2001).

Tikanga is the framework through which these values in Māori society operate. Firstly, tikanga Māori is the process through which principles are delivered or applied to any particular situation. Tikanga can vary according to waka, iwi, hapū, and whānau. For example, consider the tikanga surrounding the handling and cooking of food. The basic principles are established which include the principles of manaakitanga and its relationship to the principles of tapu (sacred) and noa (ordinary). Not sitting on or ironing of clothes on tables used for the consumption of food, and not washing clothes with table linen or the placing of hats on tables are examples tikanga observed by modern day Māori (Marsden, 2003, p.8). Such tikanga practices have their origins in ancient customs concerned with the preservation of individual mana. Principles do not change from generation to generation. Although tikanga is not fixed, it generally changes very slowly. Tikanga is the method by which the fundamental principles of Māori society are applied to different situations. Tikanga differs with principle, for example there is specific tikanga for the application of manakitanga and utu.

\section{Māori Organisations}

As Best and Love (2010) describe, indigenous business is different to Western business in that the owners, stakeholders, and beneficiaries want different things. This is in terms of the financial, environmental, social, and capital outputs from the organisation. 
Moreover, in the case of Māori business, it affects the way an organisation is managed and the way decisions are made (Best \& Love, 2010).

Māori management formations started to develop their own system and culture when Māori arrived in Aotearoa in the 1300's (Best \& Love, 2010). Before the settlement of Europeans in the early 1800's, Māori had a well-established ecosystem and economy based on kinship. Regular trading patterns were established amongst these kinship groups and iwi (Best \& Love, 2010). These traditional organisational structures were established on a foundation of shared beliefs and traditional values.

Through the urbanisation of Māori post-WWII (Best \& Love, 2010) the lure of formal paid work brought Māori back into urban areas. After the restructuring of the New Zealand economy in the early 1990's, which saw a rise in entrepreneurial structures, Māori were able to start to succeed once again in the New Zealand economy (Best \& Love, 2010). In recent years there has been a substantial growth in the small to mediumsize enterprise (SME) sector of Māori business. Yet, a contentious point is the way we define Māori business and a distinct Māori management style (Best \& Love, 2010).

One of the key points for defining Māori management is the term aronga Māori or world view (Mika \& O’Sullivan, 2014). Māori management seeks to achieve goals and purposes that benefit and serve whānau, hapū, and iwi (Mika \& O'Sullivan, 2014). The adoption and inter-relationships of kaupapa Māori, mātauranga Māori (Māori knowledge), tikanga Māori, and whakahaere Māori (Māori organisation) are a crucial part of the management of the organisation (Mika \& O’Sullivan, 2014).

A key driver of distinct Māori management systems is the attempt to retain cultural assets and cultural identity, whilst still participating in a capitalist system. Traditional Māori businesses tend to be developed using Māori values and perspectives. This is important for the integration of Māori values and preservation of these values (Mika \& O'Sullivan, 2014). As Best and Love (2010) notes, twenty first century Māori business is based on these concepts, and these concepts are deeply embedded in the way they operate.

\section{Māori Values and their relationship with business}

From a Western management perspective, a lot has been written about the integration of values and culture in a business context, much of this discussing the subsequent benefits 
to the organisation including enhanced productivity, innovation, worker commitment, and ultimately the 'bottom line.' Spiller et al. (2011) stress that values within an organisation are embedded in the choices made by the business and guide business actions, decisions, and strategy.

Such accounts tend to refer to organisation-specific values and how these might be selected, communicated, and shared in ways that drive business operations. In the context of Māori organisation, as described above, traditional values exceed the boundaries of the organisation. They shape organisational practice, rather than having organisational practice shape them. I will return to the question of values within SHRM approaches later, but at this stage it is important to consider widely held values within te ao Māori.

Table 1 outlines some of the values which have importance within tikanga Māori. The values that will be introduced form much of the ethical and social norms for Māori society, and therefore have significant implications on other issues that will be discussed later. These values can be used as a reference point for understanding why some of the issues exist and also how these are used in Māori organisations to the benefit of those working there. These include values such as kaitiakitanga (sustainability), whakawhanaungatanga (building relationships), and manaakitanga (hospitality).

I will now look more specifically at the role of Strategic Human Resource Management. It will be mainly using Western SHRM literature, with Māori management literature where possible.

\section{The Role of Strategic Human Resource Management}

In any organisation, for strategy to be successful it must resonate from the Chief Executive Officer right through to its operational arms. The following paragraphs will discuss the crucial linkage of SHRM with organisational culture, vision, values, and leadership. Without this linkage, strategy cannot be effective in an organisation.

\section{Definition of Strategic Human Resource Management}

Before proceeding, it is important to provide a definition of Strategic Human Resource Management (SHRM). SHRM can be defined as the pattern of planned human resource deployments and activities to enable the firm to achieve its goals and vision, as applied to any organisations of any type or with any goals (Wright \& Mahan, 2011). It is also 
described as a coherent, vertically-aligned, and horizontally-integrated set of learning and development activities (Garavan, 2007). Garavan (2007) also notes that SHRM must focus on creating linkages among organisation strategies, HRM systems, policies and practices. Through these definitions it is evident to see how important the relationship is between strategy and HRM. Quite simply, without strategically-oriented HRM, organisational strategy cannot be implemented effectively. 
Table 1 of common Māori values and their application in organisations

\begin{tabular}{|c|c|c|}
\hline Value & Definition & $\begin{array}{l}\text { Application in } \\
\text { Organisations }\end{array}$ \\
\hline Kotahitanga & $\begin{array}{l}\text { Kotahitanga refers to the idea of } \\
\text { Māori unity, shared sense of } \\
\text { belonging, and to the collectivist } \\
\text { nature of Māori society and culture. It } \\
\text { also relates to the role one plays as a } \\
\text { servant to whānau, hapū, and iwi. }\end{array}$ & $\begin{array}{l}\text { - } \text { Mission statement } \\
\text { - Shared company } \\
\text { values }\end{array}$ \\
\hline $\begin{array}{l}\text { Tino } \\
\text { rangatiratanga }\end{array}$ & $\begin{array}{l}\text { Tino rangatiratanga means self- } \\
\text { determination, ownership, and control. } \\
\text { It refers to self-determination to } \\
\text { preserve identity and culture. }\end{array}$ & $\begin{array}{l}\text { - } \text { Training } \\
\text { - } \text { Mission statement } \\
\text { - } \text { Aligning strategy to } \\
\text { preserve identity and } \\
\text { culture }\end{array}$ \\
\hline Whanaungatanga & $\begin{array}{l}\text { The idea of whakawhanaungatanga } \\
\text { defines an individual's responsibilities } \\
\text { to the group and the organisation, their } \\
\text { relation to others, and the } \\
\text { responsibility they have to the forces } \\
\text { surrounding the decision making } \\
\text { process (Mika \& O'Sullivan, 2014). } \\
\text { This value sets expectations on an } \\
\text { organisation developing self- } \\
\text { sustaining ethical principles to form } \\
\text { socially acceptable behaviour to others } \\
\text { (Mika \& O'Sullivan, 2014). }\end{array}$ & $\begin{array}{l}\text { - } \quad \text { Shared vision } \\
\text { - } \quad \text { Shared values }\end{array}$ \\
\hline Kaitiakitanga & $\begin{array}{l}\text { Kaitiakitanga refers to the idea of } \\
\text { Māori as guardians of natural } \\
\text { resources. This refers to the } \\
\text { implementation of responsibility on } \\
\text { Māori environmental management and } \\
\text { sustainable enterprise. }\end{array}$ & $\begin{array}{l}\text { - Taking care of assets } \\
\text { for future generations, } \\
\text { as opposed to } \\
\text { ownership and the } \\
\text { right to divest assets. } \\
\text { - Values } \\
\text { - Policies on assets } \\
\text { - Training and } \\
\text { education on the } \\
\text { importance of } \\
\text { sustainability }\end{array}$ \\
\hline Manaakitanga & $\begin{array}{l}\text { Hospitality, generosity, care, and, } \\
\text { giving. A group or organisation should } \\
\text { be able to host and provide for people } \\
\text { appropriately. Resources must be } \\
\text { allocated for this purpose. Hosting } \\
\text { may involve large groups of owners } \\
\text { and visitors. Whānau may be expected } \\
\text { to support this function. }\end{array}$ & $\begin{array}{ll}\text { - } & \text { Values } \\
\text { - } & \text { Training } \\
\text { - } & \text { Induction }\end{array}$ \\
\hline
\end{tabular}




\section{$\underline{\text { Strategy, Culture, Vision, and Values }}$}

There has been great importance recently placed on business strategy and cohesion within an organisation. SHRM asks business to align their strategy more with hiring and recruitment decisions (Marler, 2012). Milmoore (2003) refers to strategic recruitment and selection as a practice that aligns with the organisation's overall strategic vision. Culture alignment as is defined by Truss and Grattong (1994) as the extent to which SHRM contributes to organisation culture that supports organisational strategies, goals, and objectives.

Culture is widely understood to be made up of a collection of fundamental values and belief systems which give meaning to an organisation (Pettigrew, 1979). A further distinction between the two lies in the contention that the climate of an organisation consists essentially of shared perceptions, whereas the culture of an organisation is made up of shared assumptions (Ashforth, 1985).

Garavan (2007) notes that the firm's strategic orientation and alignment will influence the SHRM practices used. The firm's culture provides direction concerning the development of integrated and coherent SHRM systems. For example, it has been suggested that vision and values serve as touchstones that SHRM practitioners should utilise (Garavan, 2007). Corporate values in a classical sense can be defined as "beliefs that help companies make choices among available means and ends" (Rokeach, 1973). This definition emphasises that meaningful corporate values must be "part of the organizational decision programme" (Thyssen, 2003) and influence company behaviour. One of the main areas it influences is hiring and recruitment practices, as this is an easy way that an organisation can shape its future.

It is important to note that how Western literature defines organisational values differs considerably from how Māori businesses define organisational values (like those described above). The Western literature notes that values within an organisation are embedded in the choices made by the business, and so guide business actions (Truss \& Grattong, 1994). Māori values are integrated into an organisation by establishing their place in an organisational context. Māori values are different from Western values in their origins and intentions. Western and Māori ideas of organisations values differ, not in their application not practice, but in their origin and intention. The two interpretations of 
organisational values are not different in the sense of guiding practice but that the intention behind them is different, or the extent to which they are embedded in the past and the future.

Core Māori values are used to establish codes of conduct that convey socially-acceptable behaviour (Kuntz, et al.,2012). In a work setting, Māori values are similar to organisational values in that they guide interpretations of organisational phenomena, decision-making styles, perspectives, and inter-personal behaviours (Reid, 2011; Schnurr, Marra \& Holmes, 2007).

There are notable advantages in looking at implementing Māori values into an organisational structure. Kuntz et al. (2014) argue that using manaakitanga in an organisation enables expressions of cultural identity for its employees. Expressing the value of manaakitanga in an organisation may create pro-social behaviours and loyalty, and increase staff retention. The same is said about whakawhanaungatanga, given that it is a reciprocity value. An organisation that exhibits whakawhanaungatanga is expected to stimulate learning behaviours in the organisation, and so may have increased commitment from staff (Kuntz et al. 2014).

\section{Organisational behaviour - a Māori perspective}

As mentioned in the previous section, Māori society and its ethical principles are based on the foundation Māori values (discussed above). These values differ slightly from iwi to iwi, but the core principles present a set of common values by which Māori live. Although much research has been done on tikanga Māori in traditional Māori society, there has been limited exploration of this in the New Zealand workplace and its effect on organisation culture and worker well-being (Haar \& Brougham, 2011).

Haar and Brougham (2011) note that Māori satisfaction with cultural values and beliefs in the workplace have been significantly overlooked in the management literature. They describe cultural satisfaction at work as how satisfied employees are with the way their culture is portrayed and respected in the workplace. This is directly linked with the notion of social exchange theory. Social exchange theory relates to the giving and taking of 
benefits between employer and employee (Blau, 1964). This theory has often been described as the motivational basis behind employee behaviours (Settoon, Bennett \& Liden, 1996). If an employee receives benefits (such as respect for identity) from their organisation, they are more likely to reciprocate with positive work attitudes and therefore higher standards of work, quality, and motivation. Haar and Brougham (2011) point out the similarities between social exchange theory and the Māori value of utu (mentioned above), which captures the notion of aligning social relationships and mutual reciprocation. As such, Haar and Brougham (2011) argue that it is important to consider the attitudes and beliefs of indigenous workers, whether in New Zealand or elsewhere, since catering to cultural aspects may be an avenue for employers to gain greater reciprocity from these workers.

Haar and Brougham (2011) find evidence that the portrayal of Māori culture is significantly linked to loyalty and satisfaction of Māori workers. It is suggested that cultural satisfaction at work for Māori is a powerful influence on job outcomes because it relates to cultural values being respected in the workplace, which enhances pride in culture. It was found that cultural satisfaction at work did positively influence the work attitudes and self-reported behaviours of Māori employees (Haar \& Brougham, 2011). The implications of these findings are that Māori employees are adept at recognising support for cultural values in the workplace and respond positively to such support.

Thus, when designing organisation culture and HRM practice, there is a clear need for Māori culture to be portrayed positively and respected, in order to gain employee loyalty and to increase job satisfaction, alongside other organisation factors. This aligns also with suggestions by Ramaoorthy and Carroll (1998), who note the importance of human resource policies being culturally specific, and show that levels of individualism and collectivism are important aspects to take into account when thinking about the effectiveness of human resource policies. Haar and Brougham (2011) also point out that there is need for more research to be carried out on the potential benefits of Māori cultural expression and implementation of values in the workplace. Given the importance of Māori culture and values to an iwi entity, we might expect iwi organisations to gain even greater benefits from enhanced positive portrayal of Māori culture. 
Leadership in Māori organisations

Leadership is crucial to implementing organisational vision and values, and developing culture (Garavan, 2007). The Māori approach to leading and controlling is based around the ideals of the leader being able to "walk with a foot in both worlds" (Mika \& O’Sullivan, 2014). A successful leader in Māori business will be someone who is able to embrace and speak te reo Māori (the Māori language) and apply the tikanga, but who can also transfer into the Western world. Roche, Haar and Brougham (2015) note that the situation for Māori leaders is complex. Māori leaders nurture growth in communities that have significantly different challenges than those of Western communities (Roche et al. 2015).

Katene (2010) points out that Māori leaders are expected to lead via the engagement in, and utilisation of, unique elements of tikanga Māori and values. They should also place strong value on the ideas of collectivism, and emphasis on egalitarian values. It has also been noted that the idea of collectivism runs so strongly through Māori culture that leaders will often resist discussing their own individual achievements and will not take personal credit, placing this secondary to the importance of collective action (Diamond, 2003). This style of leadership is distinct from a Western orientation, which often places prime importance on personal accomplishments. The unique Māori leadership style has been developed within the Māori context of management arising from the circumstances leaders are put under and from the core set of values or tikanga Māori to which Māori leaders must adhere.

The main challenge of being a leader set by Te Puni Kokiri (the agency charged with providing Māori public policy and advice for government) in 2009 is that as well as leading through cultural values as mentioned above, the leader also has to achieve Western expectations such as profit maximisation. This balancing act requires a large amount of mental depth and strength. These are significant and very unique challenges for the Māori organisational leader. These challenges ask questions as to how these leaders are trained and how do they learn methods to deal with these conflicts in these roles to serve their wider community?

This trade-off between Western-style profit expectations and upholding tikanga Māori proves a tough challenge for Māori organisations. Each Māori business must examine 
what compromises must be made, in order to find a best fit candidate if it is not possible to find one that has all the qualities the organisation is looking for. Harmsworth, BarclayKerr and Reedy (2002) note that many Māori organisations today have to administer large amounts of assets on behalf of, and for the general benefit of, their constituents. The organisation must have a clear strategic purpose to ensure this happens.

The flow on effect from a SHRM perspective is that Māori business must align their recruitment, training, and induction with this overall strategic goal to service their members effectively. Only when the organisation has a strong sense of purpose can the iwi strengthen, develop, and build capacity, and most importantly retain a strong cultural identity (Harmsworth, et al. 2002).

\section{Recruitment, Induction and Training}

In this section of the literature review, I examine three main areas in recruitment that align with the literature mentioned above. I provide a base understanding and definition of these three areas in order to link their importance with overall SHRM practice. This section will explore the literature on recruitment, training, and induction and will look at the topic of what is a 'best fit' candidate for a job, and how does this strategically align with the organisation.

\section{$\underline{\text { Recruitment }}$}

Recruiting is the process of attempting to locate and encourage potential applicants to apply for existing or anticipated job openings (Compton, Morrisey \& Nankervis, 2001). In simple terms it can also be described as sourcing the right people, at the right time, in the right place, and at the right price. Writing a job description and person specification, and analysing the organisation's short, medium, and long term strategic needs and goals are two vital steps in the recruiting process (Compton, Morrisey \& Nankervis, 2001).

Figure 1 describes recruitment as an overall SHRM tool. It must involve a strategy that is consistent with overall organisational strategies which feed into each of the related human resource functions. 
Figure 1. Strategic HRM functions in an organisation

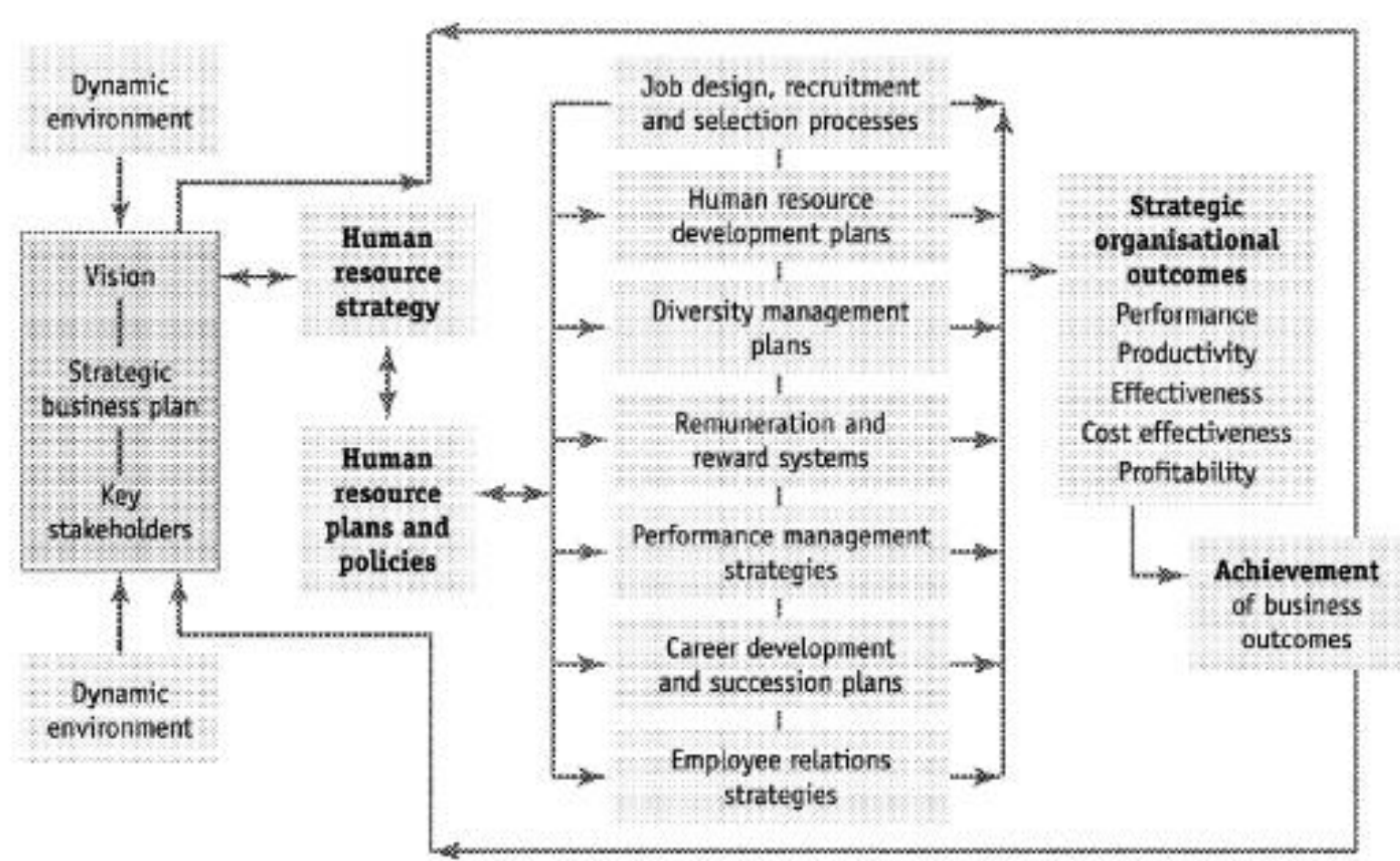

Sourced from Compton, Morrisey \& Nankervis (2001).

Recruitment and other HRM functions are an essential part of the interconnected chain of SHRM. This diagram displays the interconnected nature of the Strategic Human Resource function and its clear linkages with strategic organisational outcomes. It is important to understand that the SHRM and HRM functions are not just a role which services one purpose. HRM and SHRM link into the businesses overall strategy as demonstrated above, business success and also as again demonstrated in the diagram effects the environment within an organisation.

In acknowledging the crucial role that HRM and SHRM play in an organisation, there is now a base to discuss this is more detail. A discussion on recruitment and its role within HRM will be discussed in the forthcoming sections.

The recruitment process refers to how candidates are selected, and the method in which they are selected. The Western model of recruitment, which I outline here, presents a number challenges for iwi (discussed below). 
There are five steps in the Western recruitment process, as outlined by Compton, Morrissey, and Nankervis (2009):

1. Preparation

2. Deciding the employer or recruitment panel

3. Source the employee

4. Cover legislative aspects

5. Deciding on application methods

\section{$\underline{\text { Recruitment Sourcing }}$}

Recruitment sourcing is an important part in the process and is the starting point for establishing a job vacancy and deciding where an organisation will look for potential candidates (Avery et al., 2012). Recruitment sourcing is what identifies a business's objectives in looking at the types of people they need and from where they will source these people.

There are two types of recruitment sourcing: formal, and informal. Formal recruitment sourcing is the most common method of recruitment, and looks at hiring candidates through an 'advertisement and application method'. This recruitment style is almost exclusively used by Western business (Avery et al., 2012). Formal recruitment sourcing uses rigid systems and processes which filter out candidates, and is typically conducted with little or no contact with the candidate until later stages of the recruitment process. It is often described as keeping candidates at an arm's length and exposing them to 'pressure cooker' type situations to see what candidates are like when they are vulnerable and stressed (Avery et al., 2012).

In contrast, informal recruitment sourcing finds suitable candidates through existing relationships or by referrals from people within the organisation. Rather than advertising and asking people to apply, the organisations seek out candidates from attractive candidate pools (Avery et al., 2012).

Informal recruitment sourcing has been found to have a superior impact on employee quality over formal recruitment sourcing (Avery et al., 2012). This tends to be dictated 
by the fact that the candidate has inside knowledge of the organisation through their contact, and will therefore have a better perceived idea of what the organisation will be like. As such, potential employees are able to set more realistic job expectations (Breaugh, 1981). Potential employees also know have relationships with people within the organisation, which allows the new employee to be themselves and to feel comfortable in the organisation and more quickly contribute to workplace dynamics.

The points made above lead to the following questions: Does informal recruitment appear in Māori organisations? Does whanaungatanga also provide links to the use of informal recruitment in Māori organisations?

\section{$\underline{\text { Induction and Socialisation }}$}

The next stage after recruiting is inducting the employee into the organisation. This also includes socialisation processes. Staff induction can be defined as "the process of familiarising new employees with whatever is necessary for them to feel at home and to understand and perform their duties efficiently" (Mulders et al., 2010). Staff induction is divided into two phases: pre-entry and post-entry. The pre-entry phases can again be divided into selection and recruitment, and post-entry can be divided into orientation and socialisation. The aim of orientation is to help newcomers cope with entry stress experienced upon entering an organisation (Mulders et al., 2010).

The induction stage is where the importance of the organisation's vision and values are communicated. By communicating vision and value, the employee is made to understand the culture of the organisation, enabling the employee to effectively socialise and integrate into the organisation.

The questions that can be raised from that argument in relation to Māori organisations include: How important is induction in communicating the history of an iwi? How is tikanga communicated in the induction phase at an iwi organisation? 


\section{$\underline{\text { Training }}$}

The third step in the hiring process is the formal training and continual training of employees within the organisation.

Ekhsan and Othman (2009) describe training and induction as two of the four key functions that HRM practitioners provide. Training is necessary and critical to support organisational strategies and to grow and retain employees. Once employees are part of the organisation, a key component of on-going development is to train them clearly on the overall goals of the organisation. This is to effectively align the new candidate to get to know the organisation. Saks (1996) notes that for newcomers into an organisation, training programmes are often the most important part of socialisation.

At its most basic level, training can be thought of as the planned and systematic activities designed to promote the acquisition of knowledge, skills and attitudes (Salas, et al., 2012). Effective training takes place when trainees are intentionally provided with pedagogically-sound opportunities to learn targeted knowledge, skills, and attitudes (KSAs) through instruction, demonstration, practice, and timely diagnostic feedback about their performance (Salas \& Cannon-Bowers, 2001). The goal of training is to create sustainable changes in behaviour and cognition so that individuals possess the competencies they need to perform a job (Salas, Tannenbaum, et al., 2012). In achieving this goal, training is a useful tool in communicating organisational values and culture.

One of the most important parts of socialisation is that it provides the newcomer with information about their job, the organisation, and the strategic direction that lies within the business. Entry training therefore plays a critical role in inducting new employees.

The questions that arrive from this are; How important is it that new employees are induction properly into Māori organisations? How is this different to Western organisations?

\section{Studies on Human Resource Management for Māori and implications for Iwi Entities}

There are connections from the Western and Māori literature on SHRM that can be made to iwi entities and how they work. However, there is a distinct lack of literature which 
directly explores SHRM and how SHRM practices work within an iwi entity. This link must be made in order to show the clear implications that SHRM has on iwi entities.

On the whole, in fact there has been little or no academic research or studies conducted on iwi entities as organisations. As highlighted above, there are gaps in the research about how iwi leaders deal with the complex leadership problems they face, but there are also issues surrounding HRM practices and policies and how these can be implemented effectively into iwi entities to ensure tikanga Māori is maintained. As noted in the literature, if indeed tikanga Māori is upheld it is suggested that it may significantly improve worker satisfaction and well-being.

\section{Summary}

The review of the literature indicates that the study of Māori organisations, iwi entities, and more specifically HRM policies within these organisations, is still under-developed. As a result, my study is expected to fill a significant gap in the study of iwi entities and their HRM systems and practices. This research will be useful for iwi entering into the post-settlement phase and for Māori organisations.

The next chapter discusses the methodological process I designed and undertook in my data collection and data analysis for the current study. 


\section{Chapter Four \\ Methodology}

This chapter examines the methodological approaches, strategies, and design used in this study. The qualitative research approach used for this study will be discussed in greater detail in the discussion below.

\section{Research Question}

The study sought to answer the research question: How does an iwi entity preserve their kaupapa Māori (integrity to traditional values) through their māhi (work)?

The following sub-questions were developed to aid collection of answers to the overall research question. The sub-questions build on the literature reviewed in the previous chapter and were developed specifically to ensure that data was collected in a manner which directly answered the research question.

\section{$\underline{\text { Sub-Questions }}$}

a) What is defined as a 'best-fit' senior manager candidate in an iwi entity?

b) What challenges are most commonly associated with hiring senior managers and recruiting senior managers that are 'best-fit' for the iwi?

c) What induction policies are implemented to ensure kaupapa Māori is upheld by senior managers?

d) What type of training do senior managers undergo to ensure they uphold kaupapa Māori?

\section{Theoretical Approaches}

\section{$\underline{\text { Research Paradigms }}$}

The theoretical framework (as distinct from a theory) refers to the research paradigm of a particular study. It influences the way that knowledge is collected, studied, and interpreted. It is a set of theoretical beliefs held by the researcher about the reality of the world. These beliefs as mentioned above, guide the research process in a way that will help the researcher to uncover what they seek to find out about reality.

There are two main paradigms that generally underpin knowledge of the world and how researchers view this: the positivist paradigm and the post-positivist. 
In the positivist paradigm, knowledge exists from the positive confirmation of scientific theory through appropriate scientific methodology. Researchers conduct positivist theories to test theory. Post-positivism, on the other hand, asserts that knowledge about the world is constructed through human beings' experiences and interactions, and that reality is not fixed because there are multiple realities coexisting in the world that may be explored and studied. Researchers conduct post-positivist studies to understand what is meaningful to humans and how they create this meaning through experience and interactions.

The research paradigm I will take is a broadly post-positivist, social constructionist approach. This approach is appropriate because my study seeks to find out how people within an iwi entity preserve their kaupapa Māori, and this involves creation of social meaning through experiences with people. The fact that my study examines interactions between people in a social context further supports the use of a post-positive research paradigm. To be more specific, the subjectivist and constructivist assumptions of the postpositivist paradigm are what underpin my selection of this research paradigm.

In looking at the research paradigm to operate within, it was important for me as an individual to acknowledge I could not be objective in my study and the research. I am of Māori descent and feel very passionately about this topic and study; therefore, I had to acknowledge that there will be some element of bias in my research approach. I am applying a post-positivist approach to this study, and employing a constructivist paradigm (cite somewhere where people can read about the different paradigms). This is because I have an interested and am therefore not an objective researcher.

This paradigm is important to me as mentioned in the literature review, due to the fact that minimal research has been conducted in this area. The next section will describe the research approach within this framework. The paradigm I selected complements the kaupapa Māori research approach as discussed below. 


\section{The Kaupapa Māori Research Approach}

At the heart of this research approach is the desire for research to be conducted for Māori, by Māori, and about Māori, using Māori cultural perspectives. In conducting my research, it was always important to me that I viewed my research through a lens that made the data collection and study unique to Māori. Te ao Māori (the Māori world) elevates Māori philosophy, ethics, and knowledge into a central role (Marsden, 2003). Central to this understanding is the assumption that the whole world is an integrated system, of interconnected and multiple, overlapping hierarchies that contain complex and adaptive systems (Ruwhiu \& Cone, 2010).

It has also been noted that kaupapa Māori research offers a culturally-constituted epistemology that assists Māori researchers in their view of the world and significantly influences their research (Ruwhiu, 2016).

\section{Definition of the Approach}

By definition, kaupapa Māori research has been defined as research for Māori, by Māori, and with Māori. Kaupapa Māori research is a Māori research tradition that affords primacy to Māori cultural values and systems without reducing other values and systems (Smith 2012; Walker et al., 2006). Kaupapa Māori research sets the field of study, and defines what needs to be studied and what questions should be asked (Smith, 2012). In doing this, Ruwhiu and Cone (2010) note that kaupapa Māori research presents a paradigm that provides a template for culturally-attuned response to Māori research. Glover (1997) also described it as a desire to recover and reinstate mātauranga Māori the indigenous system that was in place before colonisation.

As a research strategy, kaupapa Māori is related to Māori ownership and preservation of knowledge and acknowledging the validity of the Māori way of doing things. However, kaupapa Māori research can be defined in the following ways, thus making it too broad to simply define as a research paradigm alone:

Kaupapa Māori as proposed by Walker et al. (2006):

- Kaupapa Māori research gives full recognition to Māori cultural values and systems. 
- Kaupapa Māori research is a strategic position that challenges dominant Pākehā constructions of research.

- Kaupapa Māori research determines the assumptions, values, key ideas, and priorities of research.

- Kaupapa Māori research ensures that Māori maintain conceptual, methodological, and interpretive control over the research.

- Kaupapa Māori research is a philosophy that guides Māori research and ensures that Māori tikanga will be followed during the research process.

Kaupapa Māori research is about Māori control, and focuses on Māori participants. Under this approach, the research design, research plan, data collection and analysis, and writeup are all completed by Māori (Walker et al. ,2006). Moreover, steps are taken to ensure that the research is conducted with the correct protocol and intention.

Kaupapa Māori research gives full recognition to Māori cultural values and systems. It locates a strategic position that challenges dominant Pākehā ways of doing research and turns research in a way that makes sense for a Māori world view and ensures Māori protocol will be upheld (Pinhama, Cram, \&Walker, 2002; Walker Eketone, \& Gibb, 2006)

\section{History}

In its earliest form, the call for Māori research came from the movement by indigenous people to increase their self-determination over land, culture and language (Glover, 2002). Secondly, as mentioned in Chapter Two, the period in which the cultural renaissance for Māori and the recognition of Te Tiriti o Waitangi lead to greater academic collaboration between Māori and non-Māori. Lastly and most importantly, this movement grew out of the dissatisfaction of Māori in the research experiences they previously had with non-Māori as well as the methodological approaches utilised (Walker et al., 2006).

Māori academics challenged the way that certain research was established as legitimate while knowledge such as Māori knowledge was deemed illegitimate (Walker et al., 2006). They also challenge the exploitative nature of much research conducted on Māori. Māori researchers have also been excluded from mainstream funding and initiatives and therefore the increased desire and necessity for Māori academics to stand out on their own 
as researchers saw them develop their own approaches and methodologies (Walker et al., 2006).

\section{Principles of Kaupapa Māori Research}

The main principle with regard to why the kaupapa Māori research movement started, is the principle of tino rangatiratanga or self-determination. This principle looks at sovereignty, self-determination, autonomy, and independence. It places emphasis on power and control resting within Māori cultural understanding and practices, and it is about a Māori-centric agenda and intention, where the issues and needs of Māori are the intention and focus of the outcome of research. As described by Walker et al. (2006), once this right to control the research agenda is established, Māori world views and ways of doing research become accepted, and legitimised as the norm.

Another important principle of this research approach is te ao Māori, or Māori world view. It refers to the Māori way of doing things and ensuring that tikanga is always respected through your actions (Henry \& Pene, 2001). In doing this, kaupapa Māori offers an epistemology that helps Māori researchers to view the world and organise research differently to a Westernised research approach. Through this I would also like to acknowledge through this my external mentors, as part of being guided by kaiārahi (Henry \& Pene, 2001). Throughout my research process, I had three external informal Māori academic mentors, who advised me on my content information, and Māori spelling and grammar.

It is important to note that in data collection for Māori sometimes only whānau are privy to certain oral stories which contribute to research. It is important, therefore, that interview responses must be treated with respect. A protocol that is important to address is that of whakawhanaungatanga - the process of identifying, maintaining, or forming past, present, and future relationships. This enables Māori to locate themselves with those in the present. The identification of these relationships then allows for in-depth information to be shared and trusted.

The principle of whānau is important. This is the principle by which Māori culture and protocols are underpinned. Whānau refers to family, but particularly includes the ideas of 
extended family and the idea of establishing relationships and connectedness between Māori (whakawhanaungatanga).

To understand the collectivist nature of Māori is central in understanding the concept of whānau. It enables knowledge to be defined and guarded by a group. This collective approach also results in Māori placing greater value on the research, accountability, protection, and care of the data and research findings. This is held as a group, rather than the onus being placed on a single individual. This principle ensures that Māori have a shared vision of research and can support each other in the undertaking of the research. For example, an individual simply claiming ownership of the research can be viewed as selfish and bad-mannered.

\section{Practical Approach}

$\underline{\text { Research Method. }}$

I will be conducting an in-depth analysis of a single case organisation. O'Leary (2004) describes the case study as a method employed to study social elements of an individual group or any other unit of social life in an organisation. Thus, case-study research is the most appropriate methodology for my particular research topic.

The case study approach, and in particular the decision to focus on only one organisation, was also selected as an appropriate method because of the limited nature of the thesis timeframe, and the scope of the thesis. The thesis scope means it is appropriate to look at one organisation and case in significant detail.

The following sections will discuss the nature of the case and participant selection.

\section{Nature of the Case}

To identify the appropriate case organisation, it is important to highlight the key features regarding what makes it unique, or in other words what makes an iwi entity's features different to those of any other organisation. The case in this study can be defined as an entity which meets the criteria as defined by the New Zealand Government as a PostSettlement Governance Entity (PGSE). A PSGE is the entity that receives and looks after redress received by a claimant group as part of their settlement. The entity makes 
decisions on how the redress is managed and how any benefits from it can be used for the benefit of all members of the claimant group. Redress can include cash, property, statutory acknowledgements, deeds of recognition and protocols with government department (Office of Treaty Settlements, 2016).

In deciding the number of case studies to use, and the limited number of iwi entities that are currently established enough to have their processes observed. In selecting the case, I chose a well-established iwi entity that was willing to share information. The selected organisation is also one that has different business arms (such as forestry, fishing, and tourism), which provides a broader range of perspectives that generate greater insight for the research.

\section{Participant population, setting and participant sample}

The target population for the study is organisational leaders, human resource managers, and senior leaders within an iwi entity.

A total of ten senior managers, organisational leaders, and human resource management leaders participated in this study. These people represented the above disciplines. In the participant population 60 percent identified as Māori, half of whom identified as being of Ngāi Tahu descent, with the remaining 40 percent identifying as Non-Māori.

\section{$\underline{\text { Data Collection }}$}

Data were collected through two main qualitative tools. The first tool was a series of indepth, semi-structured interviews; the second tool was the analysis of documents available publicly from the case study organisation. Both of these tools generated significant insight into the issues faced by iwi entities in preserving their kaupapa Māori.

The following section describes the data collection tools used.

\section{Interviewing}

For my interviewing approach I chose to do semi-structured interviews with my participants. In semi-structured interviews participants are asked a set of similar questions. I selected this method as I wanted to be able to make comparisons between the responses of different people within the chosen case study organisation. It is also coherent 
with my kaupapa Māori research approach - in interviewing people kanohi ki te kanohi (face-to-face) I was able to respect their experiences and hear their stories in person.

Semi-structured interviews are based on an interview guide containing a list of questions and topics that have to be covered (Bernard \& Ryan, 2010). The interviewer then covers each topic by asking one or more questions and using a variety of probes. Semi-structured interviews are flexible in that the interviewer can modify the order and details of how topics are covered based on the conversation with the participant (Bernard \& Ryan, 2010). At the beginning of each interview I told the participant they were able to speak either English, te reo Māori, or some mixture of both, and that I would translate it at the end. This was in order to adhere to the kaupapa Māori guidelines to ensure the participants felt they were being respected if they wanted to speak te reo Māori.

I developed the interview schedule based on the research question and sub-questions. The questions were further refined through the use of a pilot study.

\section{Pilot study}

Before I conducted my research at the case study organisation, it was important to ensure that the questions for my interview were tested to ensure I would achieve the information and results that I was intending to. In addition, I knew I needed to align my research collection with my research strategies. This was necessary to see if the strategies were an appropriate method of data collection and whether or not they would achieve my research objectives. Throughout the entire pilot study, I followed the kaupapa Māori research method to ensure robust results in the study. In this sense, the pilot study allowed me to test whether my use of kaupapa Māori was appropriate.

The pilot study was designed taking into account my research questions and subquestions, which were developed from the literature and the research gap identified. The participants in this pilot study were four employees of a public sector organisation in Wellington, all of whom were of Māori descent. These participants are ex-colleagues and were contacted by email seeking their consent and ultimately recruited for my research. I recruited two female graduates of Māori descent and two male graduates of Māori, Cook Island and Pākehā descent. 
This pilot study followed formalised procedures for conducting research, adhering to ethical guidelines of Victoria University of Wellington. Consent was gained through a form, and a participant information sheet was provided to each participant. Their interviews were digitally recorded and at the end of each interview I asked for feedback on the design of the interview questions and how the sequence of questions affected their response. Their feedback was extremely useful for changing the structure of the questions and refining the data collection method. After conducting the interviews, I shared the findings with all participants through a conversation face-to-face to ensure the research was shared with them.

During the pilot-study interviews, there were a few issues raised around come aspects of the interview questions. In the first instance, the interview questions and sub-questions were too close-ended and were leading the participants in a certain direction, rather than allowing them to tell their story. As such, my final question set was amended to be more open-ended. Secondly, the question set was not specific enough for different leaders. To correct for this, I developed two separate interview schedules corresponding to the two types of managers I was planning to interview. Thirdly, I was interrupting the participants and was not allowing time for silence and for them to be able to answer the question. Taking this into account, and also as a result of feedback from my supervisor, I then designed and refined my data collection tools in the following section to align more closely with my research objective.

Probing is the key to successful in-depth interviews (Bernard \& Ryan, 2010). The type of probing I selected to use in my questionnaire was the 'tell-me-more probe' (Bernard \& Ryan, 2010). This involves asking "could you tell me more about that" and gaining more detailed information of a story or experience from the participant.

In-depth interviews were also selected to gain a deeper understanding and to gain stories from the participants on how they maintain their kaupapa Māori at the particular organisation. It has been noted that conducting interviews in qualitative research enables the researcher to experience the setting from which the participants' experiences and stories derive. It also helps with research areas where people's experiences remain unspoken. These unspoken realties include people's interpretations, social interactions, and personal experiences. 
I recruited participants primarily through non-random sampling methods (O'Leary, 2004). The non-random sampling method I used was volunteer sampling. All of my participants were recruited through this method.

Participants' experiences were studied in one-on-one interviews where I asked semistructured questions. An interview schedule (Appendix A) and an information sheet (Appendix B) were used to guide the process and sent out to participants in advance for their consideration. They were then able to withdraw from the study or ask any questions at that stage. This was aimed at ensuring that the participants were well informed, and enabled them to ask questions about the study prior to the interview, this is important to share research/findings with other Māori in kaupapa Māori research. All communications with the participants were done via phone, email, and in person.

Before the interviews I sent participants an email with an attached information sheet and my research proposal to ensure the participants were well informed about the study and what I would be looking to gain from the interviews. In adhering to my kaupapa Māori research approach, I used whanaungatanga to build my relationships before going and visiting the participants. It was also a chance to informally introduce myself before I went to conduct the interviews.

On commencement of their interview, the participants were again provided with a brief summary of the study and research objectives. I also allowed them to ask any further questions they had and then we discussed how they would like to be identified in the research write-up. I obtained consent through a consent form provided, which informed them of the timeframe within which they could withdraw from the study, their preferred method of identification, and a confidentiality agreement. I gained permission from all participants to use their job titles and iwi name. I began by asking the participants about themselves, their background, and how they came to be working at the case study organisation. After this, I moved on to ask them more specific questions about the iwi entity and preservation of its kaupapa Māori through SHRM policies and strategies and their own experiences. At the end of the interview, I discussed the thesis topic with them. I then thanked them for their significant contribution to my study. It was important for me to show my gratitude in their willingness to participate. 
The duration of each interview was approximately 45 minutes, and each interview was digitally recorded. All interviews were completed in English, although some Māori and English words were used interchangeably throughout. Where appropriate, the Māori words used in the interviews have been translated into English after the interview. On the day on which each interview was completed, I documented my initial thoughts from the interview. Then about six weeks later, I transcribed the interview and followed up any ambiguous data with the respective participant through email.

\section{Document Analysis}

Document analysis is a useful tool used for collection, review, interrogation, and analysis of different types of documents (O'Leary, 2004). This tool was extremely useful to my research. The main purpose of document analysis in my research was to act as support to my interview data. A secondary benefit of document analysis is that, due to the limited time constraint on the thesis, document analysis is an efficient way to gain data because it does not require people's involvement and is not disruptive to the organisation. Lastly, using document analysis in this particular study provided in-depth information and insight about how kaupapa Māori is preserved in HRM policies and induction.

\section{$\underline{\text { Limitations of Document Analysis }}$}

There are two major limitations of document analysis as a data collection method that must be acknowledged. The first limitation is the role of the researcher to collect, review, and analyse relevant documents and the extent to which documents may be available from the organisation. Therefore, the researcher may be bias in the way they select the documentation. The second limitation is that the researcher can view the content of the documents from her or his own perspectives, making it biased to the researcher's views regardless of whether it is compatible with the author's points and intentions for the document. 


\section{Data Analysis}

In this section I will discuss the method of qualitative data analysis used and then the procedure for analysis.

Thematic Analysis

I analysed my data using a non-numerical analysis method called thematic analysis. This involves the identification of key themes as they appeared in the data. I considered this to be the most appropriate type of analysis because it looks at the significance from the participants' interpretations, stories, and experiences.

Bernard \& Ryan (2010) describe three principles for identifying themes. Firstly, themes are only visible through the manifestation of expression in data. Secondly, some themes are obvious and culturally agreed upon, but others are subtle and symbolic. Lastly, cultural systems comprise sets of inter-related themes. It is also noted that the importance of a theme is related to how often it appears, how pervasive it is across different types of cultural ideas and practices, how people react when the theme is violated, and the degree to which the force and variety of a theme's expression is controlled by specific contexts.

The thematic analysis in this study occurred on two levels: analysing the individual interviews, and comparing and contrasting the different interviews conducted and documents collected. To analyse the themes I used the eight observational techniques proposed by Bernard \& Ryan (2010). These techniques are:

1. Repetition

2. Indigenous typologies or categories

3. Metaphors and analogies

4. Transitions

5. Similarities and differences

6. Linguistic connectors

7. Missing data

8. Theory related material

In the first thematic analysis, in which I looked at each individual case, I used Bernard \& Ryan's (2010) 'cutting and sorting' technique. This involved identifying quotes or expression that appeared important, called 'exemplars'. I identified exemplars for all 
interviews as well as for the documents used for document analysis. When the exemplars were identified I placed them into the summary category. This framework is based on Tolich \& Davidson's (1999) framework. Once these were identified, I then arranged the exemplars into similar piles corresponding to different themes. I placed them in my second column of the framework, i.e. the positive coding category of the framework. The third column is for negatively coded data or data that was unclear. This was done for each individual case.

After identifying the common themes, I noted the themes that emerged for each individual case on different cards. I then continued into my second level of analysis by comparing each individual case against the others. This process also employed the 'cutting and sorting' technique. This is where I grouped respective themes emerging against each other. I then placed these in one framework for the entire data set so that it compared the data across individual case studies.

\section{Research Credibility}

Given that my research for this thesis has been shaped by the underlying assumptions of the post-positivist and social constructionist paradigm and influenced by the kaupapa Māori research approach, I must acknowledge my subjectivity as a researcher. With this in mind, I have put measures in place to ensure research credibility throughout my data collection.

The first action I undertook to ensure research credibility was to use the guidance of my research question commencing from the literature review through to the qualitative data collection. This is to ensure that the conclusion is consistent with what I need to know about the preservation of kaupapa Māori in the organisation. It has been noted that if the conclusion is drawn from outside the observable phenomena then the research is not valid (O’Leary, 2004). To ensure I aligned with my research question, I constantly referenced my core research question as my guide.

The second action was to ensure research validity throughout the various data collection methods I utilised. To ensure I did this, I ran a pilot study, used more than one data collection tool, interviewing and document analysis, and tried to employ participants from a different range of occupation within the case study organisation. 
Thirdly, I take full responsibility regarding ethical issues in the research process. One of my roles as a researcher is to make the participants fully aware of their right to confidentiality in the research. My responsibility is to also ensure that research documents are kept safe. The documents are now electronically secured on a secure database and locked with a password. In giving the participants the option of confidentiality it enabled them to trust me in the research process and to talk to me with confidence. Building a good relationship with the participants and maintaining this rapport is important to me to ensure research credibility (O'Leary, 2004). It is also important as I hope to share my findings with the individuals and to be able to use my research to give back to the iwi.

\section{Summary}

The exploration of research strategies identified the post-positivist and social constructionist paradigm and its assumptions as an appropriate method for this study. I also identified the kaupapa Māori research approach and its assumptions as an appropriate approach to take. Both these approaches complement each other in their assumptions. I decided to use a qualitative data collection approach, alongside a case study approach. I employed two tools within this approach - in-depth interviews and document analysis.

After organising the data, the findings were arranged into common themes, linked to the original research question and the objectives of the study. The results and findings are presented in the next chapter. 


\section{Chapter Five \\ Findings}

The discussion will start with an introduction of the iwi that acted as the organisational case for thus study - Ngāi Tahu. In order to provide context for this study, the story of Ngāi Tahu will be told from the first arrival in Aotearoa, through to the inception of the modern iwi entity. The discussion will then look at the challenges associated with using traditional values of Ngāi Tahu in an operational context, and what conflicts exist in preserving these traditional values. Finally, chapter will describe the strategies used by the iwi to ensure these kaupapa Māori values are upheld using formal and informal mechanisms.

\section{Ngāi Tahu - The Iwi}

They were the first long-distance seafarers, riding the ocean currents and navigating by stars on voyaging waka (canoes) from Hawaiki Nui. Ngāi Tahu people populated the islands of the South Pacific, eventually making their way to Aotearoa and Te Waipounamu (Ngāi Tahu, 2016).

Waitaha, the first people of Te Waipounamu, journeyed on the Uruao waka and settled in Kā Pākihi Whakatekateka o Waitaha - the Canterbury Plains. Ngāti Māmoe and then Ngāi Tahu followed. Through warfare, inter-marriage, and political alliances a common allegiance to Ngāi Tahu was forged. Ngāi Tahu means the 'people of Tahu' (Ngāi Tahu, 2016). Within the iwi there are five primary hapū (sub-tribe): Kāti Kurī, Ngāti Irakehu, Kāti Huirapa, Ngāi Tūāhuriri, and Ngāi Te Ruahikihiki (Ngāi Tahu, 2016).

Ngāi Tahu formed permanent and semi-permanent hapū settlements in coastal and inland regions supported by an intricate network of mahinga kai (customary food gathering sites). Whānau travelled seasonally between mahinga kai sites where they farmed seafood, eels, birds, and plants, leaving traditions, knowledge, and rock art to guide future generations (Ngāi Tahu, 2016).

Ngāi Tahu had an economic stronghold in pre-European New Zealand. Hapū traded pounamu and other resources regionally and nationally. By the 1830's, Ngāi Tahu had built an industry supplying European whaling vessels. Ngāi Tahu were hospitable towards European whalers and settlers. 
After the Ngāi Tahu ancestors signed Te Tiriti o Waitangi, Ngāi Tahu entered into contracts with the Crown to sell some of their land, with the promise of the creation of reserves sufficient for people to thrive, as well as the provision of key social infrastructure including schools and hospitals (Ngāi Tahu, 2016).

However, the Crown did not honour its obligations under the Treaty (as discussed in chapter two). Ngāi Tahu were forced into being a people almost devoid of land, depleted by disease, and divorced from the growing economy.

\section{Te Rūnanga o Ngāi Tahu}

Te Rūnanga o Ngāi Tahu, the tribal council, was established by the Te Rūnanga o Ngāi Tahu Act 1996 to be the tribal servant, protecting and advancing the collective interests of the iwi.

The design of Te Rūnanga embraces traditional methods. It uses corporate governance models and draws from the democratic structures of local government and Western best practice. Te Rūnanga board members are appointed following a democratic process and are responsible for the governance of tribal assets and investments in tribal development (Ngāi Tahu, 2016).

The initial asset base of Te Rūnanga was largely derived from the assets of the Ngāi Tahu Māori Trust Board and from the settlement of Te Kerēme - The Ngāi Tahu Claim. The financial settlement, which was received in late 1998 , amounted to $\$ 170$ million plus some interest and commercial opportunities (Ngāi Tahu, 2016). It also subsequently involved fisheries and aquaculture assets valued at \$71 million.

One of the principles of the Charter is that the assets of Ngāi Tahu must be managed separately from the bodies that spend and distribute the income earned from those assets (figure 2 shows how the Ngāi Tahu organisation is structured). As such, the executive functions of Te Rūnanga are carried out by the Office of Te Rūnanga which manages the representational activities, protects the rights of Ngāi Tahu Whānui, and delivers social and cultural programmes. The case organisation, Ngāi Tahu Holdings Corporation, manages commercial activities and assets. 
Te Rūnanga has an inter-generational investment framework designed to ensure a steady and sustainable cash flow based on profit and capital growth matching its intergenerational tribal development strategy. It includes stringent benchmarking and spending rules as well as a strategic asset allocation framework (Ngāi Tahu, 2016).

Annually, Te Rūnanga issues Letters of Expectation to the Office of Te Rūnanga, Ngāi Tahu Holding Corporation, and Whai Rawa, the Ngāi Tahu savings programme for members which set out general and specific expectations regarding activities and performance. In response, these business units develop detailed Statements of Corporate Intent, setting out how they will fulfil those expectations (Ngāi Tahu, 2016).

The development strategy of Te Rūnanga is aligned to a tribal distribution strategy. This sets in place an overall strategy for the tribe's investment future, commercially as well as in people and the tribal development (Ngāi Tahu, 2016). 
Figure 2. Organisational Structure of Te Rūnanga o Ngāi Tahu (Ngāi Tahu, 2016).

Te Rūnanga o Ngãi Tahu Organisation Structure

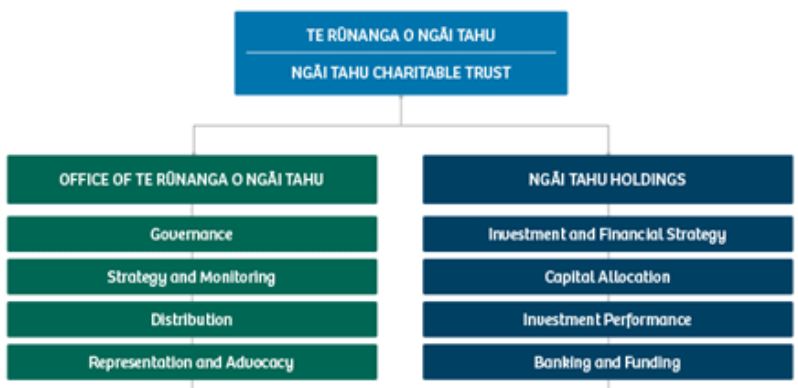

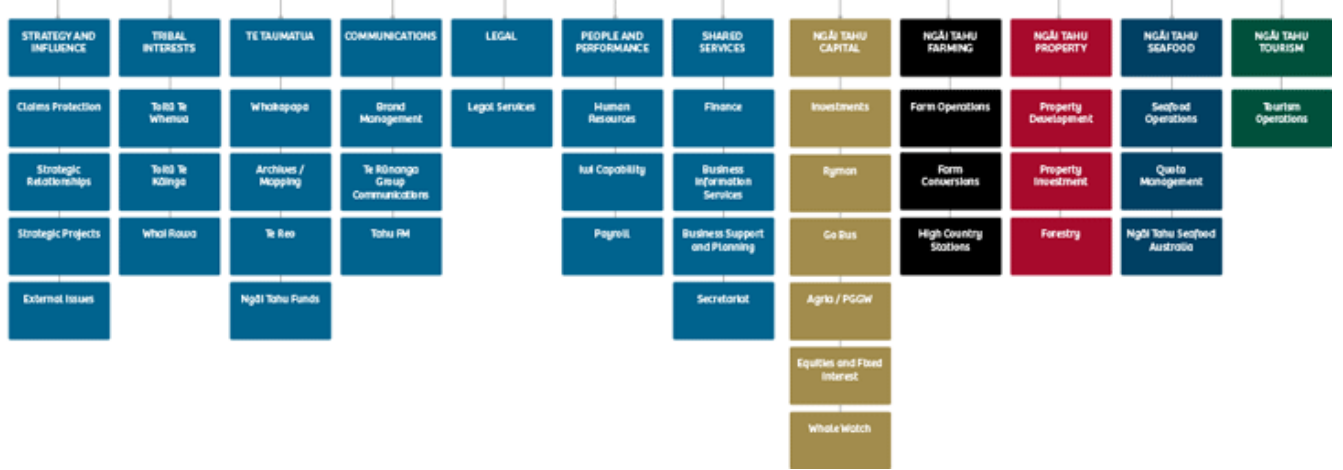




\section{Context}

Prior to the discussion moving into looking at the thematic analysis, I would like to make the following acknowledgments about the case study and context.

The first aspect of this context is the nature in which the organisation or entity was formed. As mentioned in chapter two, an iwi entity is formed out of a settlement from the government, for past breaches of Te Tiriti o Waitangi. Its formation is determined by a set of government legislation.

Thirdly, in looking at the culture of the organisation it is important that the nature of the organisation is established. The iwi entity wears many hats as an organisation. It can be described as a profit-maximising firm in its need to invest, reinvest, and gain capital. It can be defined as a family business, because an iwi is a tribe to which whānau and hapū belong. It can also be described as a not-for-profit organisation, so it can be distributed throughout the iwi and its members. In knowing the nature of the firm we can ascertain its identity.

Fourthly, the nature of this firm is that there are different arms to the business. Therefore, the participants' experiences will differ and be somewhat biased by the specific context of their employment with the iwi.

The following section discusses the findings from the analysis conducted on the interviews with participants and document analysis. Each quote after it will have the interviews role, and what part of the Iwi they worked in. This is to provide the context of their quote and to show the different perspectives given. There will be either NTH, which is the acronym for Ngai Tahu Holdings, or TRONT, which is the acronym for Te Rūnanga O Ngai Tahu.

\section{Kaupapa Māori and Strategy}

"We have our values and they're incredibly important" (CEO, NTH) 
The values represent ancient traditions that have carried through from the first Ngāi Tahu people who migrated to Te Waipounamu right through to the modern iwi entity. They are more than just corporate values, they are values which have grown with the iwi in its existence and are now reforming themselves in a business setting.

In this section I will discuss the high-level strategic use of values in the organisation. Then the discussion will move on to address in more detail the values of kaitiakitanga and manaakitanga as two specific values that emerged.

\section{$\underline{\text { Kaupapa Māori and Values in Operations }}$}

The engrained use of values in the organisation emerged as a key point for many participants. Values are a way of carrying through the tribe's identity into a business context. Throughout the interviews, I noticed participants relating business activity, organisational decision making and operations to values. These values were foundational concepts to the way the organisation operated. These values are core to its identity as an iwi entity.

When asked how values were looked after and used in the organisation, a lot of the participants mentioned the Ngāi Tahu 2025 plan (a document that will be discussed in further detail later in the discussion) as a basis from which they gained their understanding of the values in Ngāi Tahu:

"Your values are written into your corporate documents, letter of expectation, strategic annual plan..." (Deputy Kaiwhakahaere, TRONT)

The quote above discusses how these values are communicated to members within the organisation. It is important that they are documented.

The perception I gained from participants is that there is a want and need for these values to be entrenched into the way things are done at the iwi, from everyday operations through to high-level strategic decision making.

The organisation has recently begun the process of using more formal procedures (discussed more fully later) and highlights the importance of these activities lining up with the kaupapa or strategy of the organisation. As noted by a leader at the organisation: 
"Everything we do lines up behind that overall kaupapa at the end of the day"

The expectation surrounding the iwi entity and what they do is a significant reason why it is important that values line up with strategy. As noted by one of the participants, there is a certain amount of responsibility that is placed upon the shoulders of the leaders that work at the organisation, to not only make sound business decisions but also to make decisions that are cohesive with the iwi:

"So we carry the Ngāi Tahu name and I think that comes with a responsibility so we are a Ngäi Tahu business and the iwi want us to carry out business in a way that's consistent with their expectations and their values and add to the build of Ngāi Tahu brand." (CEO, NTH)

This notion demonstrates the tension between Western business expectations and traditional Māori values. NTH acknowledges that people must be taught these values; what may be inherent to them is not to others:

"That's just a simple example of talking about values that you would hope to see in our behaviours. So what's inherent to us isn't inherent to others." (Deputy Kaiwhakahaere, TRONT)

\section{Manaakitanga}

There were two core values that participants used to describe their work and organisation and how they operated.

"One of the key things for Ngāi Tahu is manaakitanga and how we look after those who come into our home" (Deputy Kaiwhakahaere, TRONT)

The first of those values was manaakitanga, which relates to concepts of hospitality, generosity, care and giving. A group or organisation should be able to host and provide for people appropriately. Resources must be allocated for this purpose. Hosting may involve large groups of owners and visitors. 
Unlike iwi in the North Island, Ngāi Tahu members were spread out across the South Island and so often were travelling. The idea was that you welcome those travelling into your home. This value has translated in itself now into an organisational context.

Those participants who identified as Ngāi Tahu articulated a strong connection to this value. When asked about her background, one participant told me about her history and noted the importance of this value in Ngāi Tahu's history. This history, and where her family was from, was mentioned numerous times in talking about the organisation and the value of manaakitanga.

"Think about what our expectations are back home, so one of the key things for Ngāi Tahu is manaakitanga and so how we look after those that come into our home, into our whare" (Deputy Kaiwhakahaere, TRONT)

In a business sense this translated into small actions within the organisation, which nonetheless demonstrated the pervasive importance of Māori values. For example, participants reported that they always made sure that visitors were offered a cup of tea on arrival, and stressed the importance that the tea is being offered by the person hosting the visitor. In my trip to NTH for the interviews, I experienced this act of manakitanga first hand - upon entry to all of my interviews I was asked if I wanted a cup of tea or coffee and the interviewee then went and made me a cup of tea.

\section{"Manaakitanga needs to be strong in all that we do inside the corporate organisation" (Deputy Kaiwhakahaere, TRONT)}

This value also appeared to give the participants a sense of belonging and something they could share with me about Ngāi Tahu and Ngāi Tahu Holdings Corporation's values.

Although the value of manaakitanga was widely shared, there were differences across the different arms as to what contexts and situations within which it was valued. Notably, it was mentioned a lot more by the senior managers as opposed to the Human Resource Managers, and was a value that was tied more closely to those who identified as Ngāi Tahu as opposed to those who did not. The connections that can be drawn between certain 
values and those participants that identified as Ngāi Tahu highlights how the origin of Māori values is largely driven by cultural practice.

When discussing with participants how they felt values they had learned at home and outside of work carried into work they mentioned the 'tribal' values that their families lived by. Therefore, these traditional values came through not only in home and family life, but were also something that they felt was important to then carry through into the way they worked at the organisation.

The ingrained use of this value is one demonstration of how participants perceive that they are carrying through their kaupapa Māori inherently in everyday operations at the iwi entity. Manaakitanga is a value that has carried through from tribal and historic times right through into the business context.

\section{$\underline{\text { Kaitiakitanga }}$}

As, discussed in chapter three, kaitiakitanga refers to the idea of Māori as guardians of natural resources and the environment. A breakdown of the definition of kaitiakitanga is derived from the verb 'tiaki' (to guard; to protect; to keep; to watch for; to wait for) - with the prefix "kai" denoting the human aspect of the action. Hence a "kaitiaki" can be translated as a guardian, and kaitiakitanga the act of guardianship (Roberts et al., 1995) to preserve values for future generations. This principle imposes responsibility on Māori to act according to sound environmental management and sustainable enterprise.

Kaitiakitanga ties into iwi entities in their role as a not-for-profit organisation and as a family business. The business decisions made by the iwi are made not only to generate profit now, but to generate capital and make investments, in a way that will benefit and not hinder the future generations of the iwi.

Māori being guardians of the land and environment is an idea that is evident through the way that the iwi's employees identify themselves. When asked to describe the organisation one of the first things one of the participants said was:

“We're inter-generational....." 
This inter-generational mindset affects the way decisions are made within and for the organisation, in order to ensure that their kaupapa is maintained. When participants were asked about their perceptions of how kaupapa Māori is maintained, many said it was maintained through the decisions they made within the organisation and thinking about the impact this would have on future generations. It was perceived by many as the most important choice their leaders could make.

This was particularly an issue when looking to expand business. One participant was discussing in which industry the next business venture would be. The participant discussed the iwi going into farming and agriculture, but noted the drawbacks of the negative environmental impacts of farming (for example through discharging pollution into the environment). The participant voiced the question of whether moving into farming and agriculture is consistent with maintaining kaitiakitanga and thus their kaupapa? The quote below is discussing the idea of sustainability:

"In an environmental sense as well as the sustainability of the business" (in relation to decision making about whether or not to get into agriculture). (CEO, NTH)

This statement highlights that considerations must be made so that traditional guardianship values are not compromised solely for profit.

Many of the participants noted that the way they acted today would not affect them, but would affect the next generations.

"You have the burden of grandchildren, the silent voice to go to the decisions we make today could have positive or detrimental impacts on our great grandchildren" $(G M, N T H)$

The participant describes kaitiakitanga as one of the underpinning values of the way the iwi operates. They must make conscious decisions from a business perspective that will add benefit and not hinder future generations. Therefore, kaupapa Māori is maintained through the emphasis from the iwi members that they are guardians of the land and 
therefore guardians of the future for their people. In order to be consistent with this iwi value, NTH must also build this value into their business decisions.

Participants were given a chance at the end of the interview to say one last thing. One participant said:

“What I want to signal to you is that we're only here for a short time but really what we're trying to do is contribute to future generations" (GM, NTH)

This statement emphasises the importance of kaitiakitanga in maintaining kaupapa Māori. Participants' perceptions of decision making (both by themselves and by leaders within the iwi) are heavily influenced and guided by how today's decisions will impact on future generations.

"I think there are some characteristics that come from the iwi primarily in terms of value based investment, long-term, sustainable view to business, all those types of stuff”. (CEO, NTH)

It is also evident that the definition of sustainability in an iwi entity context looks not only at the environment as it does in a traditional sense but also refers to people.

Kaitiakitanga emerges mainly through the decision-making process at the iwi. This is where most participants have noted its importance. It also appears in the iwi entity's overall strategic document, in NTH's mission statement.

In the Ngāi Tahu 2025 plan, there are seven main pillars upon which strategic decisions are based. One of those pillars is specifically the environment and how NTH, as guardians of the environment, can help to preserve it and to make environmentally-conscious decisions. As demonstrated in the following quotations from this plan, we can see that it is something that is central to their way of doing things and way of being:

"Our natural environment - whenua, waters, coasts, oceans, flora and faunaand how we engage with it, is crucial to our identity, our sense of unique culture and our ongoing ability to keep our tikanga and mahinga kai practices alive." (Page 8, Ngai Tahu 2025 Plan) 
And:

"How we engage with our land and its coasts is crucial to our identity, our culture and our tikanga” (Page 8, Ngai Tahu 2025 Plan)

In compiling the data from the document analysis as well as the interviews, it is demonstrated that through written and verbal form, there is much emphasis placed on thinking about the impact of today's decisions onto future generations. Sustainability is extremely important to the way that Ngāi Tahu operates.

From both the interviews and the document analysis, kaitiakitanga was identified as being split into three meanings in different contexts. It is used in reference to:

1. whenua (land), waters, coasts, flora and fauna, and the physical environment.

2. the sustainability of the people within the iwi, and how they grow.

3. the intertwining relationship between sustainability of the environment, and the preservation of tikanga practices.

(Page 9, Ngai Tahu 2025 Plan)

These three meanings providing the basis on which the remaining analysis is built.

\section{Challenges to balancing these values with business success}

While these values are critical and are held up as important, their maintenance is not so straightforward. Some participants felt that the kaupapa is not as strong as it should be. This discussion describes the limitations and constraints placed on iwi in commercial environments in balancing traditional kaupapa Māori values with day-to-day business operations. Many of the participants discussed the nature of the organisation and described some of the conflict that exists for them:

"So you have a very strong pākehà economic context and so the organisation has to fit a pākehā economic context and behaviours ... organises, thinks in a way to fit in but then it's accountable to an indigenous community that thinks in a very different manner so you are trying to balance this huge tension between economic priorities and cultural." (GM, NTH) 
The first of those conflicts being the dichotomy that exists between the nature of financial gain and cultural gain. As one participant stated, they have two aims:

"One [aim] is to maintain and grow collective capital so you can do what you want and the other is to maintain and grow collective cultural capital or identity so that we are always our people and we have a living language and culture and most organisations are for profit, we are like a not-for-profit, that makes our own profit". (GM, NTH)

The participants had different perceptions and experiences depending on the area they were working in within the business and again this was affected by their own work and cultural background. One of the participants described the motivation for profit being different in this context:

"We are not simply generating profit so that the CEO can afford another house in the Bahamas. We are looking to gain profit so that this can be reallocated throughout the iwi, to improve the well-being of its members". (CIO, NTH)

The quote above indicates an employee's perception of one of the main differences between working at an iwi compared with working at their previous (Western business) employer. This contrasting motivation was expressed in many of the interviews by the participants; their job at the iwi is challenging and at the same time rewarding, mainly because of the reallocation of profit rather than the gathering of profit. This theme was particularly evident in the interviews conducted with participants from the investment and holdings arm of the organisation.

The second challenge I discussed with the participants was the perception of the iwi as a business. It was noted by one of the participants that as they started to float Ngāi Tahu Holdings as an investment organisation, initially they had struggle to gain buy-in from other organisations due to the nature of the business and their status as an organisation.

"A question we regularly got asked (vis-à-vis investment) was 'are you going to compromise financial returns for social outcomes?'." (CIO, NTH) 
There was an external perception that the values Ngāi Tahu were trying to uphold, the commitment to whānau and community and future generations, would compromise financial gain and investment. Therefore, compromise and conflict exists not only within the business with regard to maintaining kaupapa Māori but also with external organisations as a result of perceptions of the impact of these values on the iwi entity as a viable business. They responded to this perception by creating specific strategies so that there were quality assurance checks on the organisation, this way they could prove and ensure for themselves and others they were upholding these values.

Another theme that emerged relates to nature of the firm as acknowledged in the context section in that the organisation exists with a number of inherent complexities due to its 'family business' structure and the accountability that exists within this.

"It's different; it's a family business at the end of the day and what you do is meaningful and you've got to front up to them face to face”. (CIO, NTH)

The last, and perhaps most significant, conflict for the iwi entity is finding a balance between incorporating Western business structures into an iwi context. This can be defined as finding an identity the iwi wants to reflect to the outside world. NTH is currently reviewing various different business models and ensuring that they employ a business model that is conducive to, and does not compromise, the iwi entity's values. For example, many of the comments made by participants related to how Ngāi Tahu are currently trying to find their strategic direction and identity as a business. One of the participants believed Ngāi Tahu's kaupapa is "lost" at the moment, they are in the stage where the business is formed and established and they are trying to figure out where they want to take it from this point.

One of the tensions within this challenge is diagnosing what works, what doesn't, and essentially what is or isn't Māori. The organisation is looking critically at the way they work and the structures they use. They are trying to create new ways of working that fit best with their strategic approach and their identity as an iwi organisation. It is central and critical for the iwi entity to get this right, in order to ensure they maintain their kaupapa in the way they operate. In being able to look critically at themselves, the iwi entity is pursuing a more culturally-centric way of working. 
"And one of the big tensions is how do we diagnose them as being pākehā, figure out which technical bit we might want to keep, and what cultural bits we want to reject and replace with our own cultural values or culturally inspired alternatives." (GM, NTH)

"Yeah there's huge challenges. I think from settlement we established the postsettlement entities and then all of a sudden we hit the ground running. The expectations were huge. The expectations from whānau were huge, the expectations from those external of us, you know, all eyes are upon us. Secondly we needed to sign off on settlement, so all eyes are on us. We hit the ground running. In those days I suppose honestly you could say we weren't actually that ready for the overwhelming expectation that was upon us. Kaupapa Māori environment you've got very much claim, we're all in battle mode, we're all in grievance mode. We've all got this commonality of a war that we're fighting, which is settlement." (Deputy Kaiwhakahaere, TRONT)

The next section will address people management practices of recruitment, induction and training currently being implemented at the organisation. It will also discuss formal strategies that sit above the recruitment, induction, and training in order to ensure that the core values of Ngāi Tahu are being communicated and ingrained into the organisation within the framework of strategy.

\section{Strategies for Incorporating Traditional Māori Values}

Ngāi Tahu is making significant efforts to ensure that kaupapa Māori is maintained in their work and their values are being maintained in the work they do. This seemed to take shape in formal ways, policies, procedures, and documents and through specific recruitment, induction, and training processes. As previously discussed, these efforts are evident through various informal mechanisms, such as social norms and teaching by other members at the iwi.

\section{Formal Policies and Procedures}


The following discussion will review in more detail the tighter policies and controls that Ngāi Tahu are implementing, in particular the types of documents used, strategic recruitment tools utilised, as well as informal and formal training and induction.

\section{Quadruple bottom line reporting}

This reporting looks at measuring a business's success based on four elements.

Financial, environmental, social and cultural.

One of the themes that came out in the interviews was the idea of quadruple bottom line reporting. The iwi was looking for a way to 'measure' the use of values in the organisation:

"So we're changing to quadruple bottom line reporting, so there'll be that values reporting. And that's something new. We've been talking about that for probably five or six years, and we still haven't got it. So we're changing to that." (Deputy Kaiwhakahaere, TRONT)

Currently, quadruple bottom line reporting still a work in progress and is still being developed at the iwi. The idea of using the quadruple bottom line reporting would be a way to ensure that the values are being used and measured in everyday business. As one participant described, quadruple bottom line reporting is a way to bring the values to life in corporate speak:

“....Is that the values sort of translate themselves into corporate speak into something called quadruple bottom line reporting. And again if you like, that is giving our values life as well. So it's beyond just the bottom line in a financial sense as well". (CEO, NTH)

Thus far, the idea of quadruple bottom line reporting has been used in the agriculture sector of the business and has been trailed in that setting:

"It shouldn't be hard to develop that framework... Because this is farming is new to us, it's contentious, a large number of whānau didn't want us going into farming so we have to go really overboard to ensure we're collecting the right 
data, it can be demonstrated that we're not polluting any waters. So in a sense we've got that quadruple bottom line going on our farms, so it shouldn't be that difficult to roll it out across our whole organisation." (Deputy Kaiwhakahaere, TRONT)

\section{Documents}

Documents are used as a formal means of communicating strategy and values. At Ngāi Tahu there were three main documents that were introduced and these will be discussed further. These documents are used to stream communication about values to all the business arms. As the organisation grows, so does the length from the head of the organisation through to the small branches. As this happens, these formalised documents become more essential to the way Ngāi Tahu communicates strategy and operates.

The reason these documents are compiled and published is to ensure that kaupapa is met and forms an integral part of business operations. These policies and procedures are used as solid documents and strategies:

"Because the commercial arm is at arm's length from us, we give a letter of expectation that says this is what we expect of you. It says you will ensure that you abide by and adhere to the tribal values, you will ensure that you have a goal of x percentage of stuff will be Māori, will be Ngāi Tahu." (Deputy Kaiwhakahaere, TRONT)

\section{The 'What is an Investment?' Document}

This document is used by Ngāi Tahu Holdings. When asked to describe the nature of their job one of the participants brought up the document:

"We are tasked with putting money to work in a manner that delivers a return that is sustainable and in accordance with 'What is an Investment?'- a document which governs the relationships between Te Rūnanga and Ngāi Tahu Holdings, which sets out various rules or guidelines around what the distribution will be, to fund charitable programmes, what investments we'll undertake, so a bit of a 
guidance as opposed to just a blank sheet of paper and go invest, if you like." (CIO, NTH)

This document is provided to all members and employees of Ngāi Tahu Holdings with the expectation that this is the framework they use for deciding whether they are going to make any specific investment.

As per the organisation chart mentioned above, the holdings arm of Ngāi Tahu specifically looks at the investment portion of the business. The 'What is an Investment?' document is aimed at ensuring that there is quality control and consistency in place relating to how the organisation makes decisions and ensures that they adhere to the kaupapa of the organisation. The quote below demonstrates this point:

"We can impose policies that will ensure the behaviours operate in a certain way. So one thing that we developed a few years ago was an investment policy framework so that's Te Rünanga's investment policy framework, it guides how our commercial guys behave, the transactions they can make (and) what have you. And in there, there's a values section and I really want to beef that up." Deputy Kaiwhakahaere, TROPNT)

This quote demonstrates why this framework was created, and also noting that even still, they feel there is room to "beef up" the values section.

As mentioned in the conflict section, there is a large amount of accountability when making these decisions as opposed to just making choices with no awareness of the consequence.

\section{Letter of Expectation}

The Letter of Expectation is defined by one participant as follows:

“Annually Te Rūnanga issues Letters of Expectation to the Office of Te Rūnanga, Ngāi Tahu Holding Corporation, and Whai Rawa which set out general and specific expectations regarding activities and performance. In response these 
business units develop detailed Statements of Corporate Intent setting out how they will fulfil those expectations". (page 48, Ngai Tahu 2025 Plan)

Again, the Letter of Expectation document provides a quality control measure as well as a formalised way of communicating the expectation of the iwi on business operations. This document aligns with objectives and again as with the document above, sets expectations so that each arm is held accountable to the iwi and upholding and adhering to its values and kaupapa.

\section{$\underline{\text { Ngāi Tahu } 2025 \text { Plan }}$}

The Ngāi Tahu 2025 Plan document exists to ensure that each generation learn lessons from the past and prepare for the future:

"Ngāi Tahu 2025 is our vision; many have contributed to its creation and all will benefit from its continued existence". (Page 6, Ngai Tahu 2025 Plan)

The planning process started with the appointment of the Vision Focus Group. These were Ngāi Tahu Whānui charged with “dreaming”. Dreaming of the future; of where their whānau, hapū, and iwi would be in 25 years, what they would look like, and what the world would look like. Extensive consultation with kaumātua, Ngāi Tahu Whānui, Papatipu Rūnanga, Te Rūnanga o Ngāi Tahu, and staff occurred before Vision 2025 was presented to the tribe at the 2000 Hui-ā-Tau held at Kaikōura.

Te Rūnanga o Ngāi Tahu then entered into a process of consultation. Ngāi Tahu 2025 was discussed at fourteen hui held throughout Te Waipounamu (the South Island) and Te Ika a Māui (the North Island) and at various wānanga.

Ngāi Tahu 2025 is described as a "living document, subject to annual revision and change, as is the environment in which we operate". The subsidiaries of Te Rūnanga o Ngāi Tahu will be required to develop specific strategies that deliver the document and they will be measured against these on an annual basis. Likewise, Te Rūnanga o Ngāi Tahu will report progress towards compliance with Ngāi Tahu 2025 in its annual report each year. 
This is the overall strategic document, from which the other two documents derive. The documents link the entire organisation to work in a manner which is homogenous across the organisation. As mentioned above, with the commercial activity of the iwi growing and with certain arms of the organisation becoming more distant from the centre, it is crucial to have documents like this to guide every part of operations. These documents work as a quality assurance check. The aim is that everyone making decisions should be using this document as a reference point. Similarly, the document acts as a formal record against which people are held accountable.

\section{Recruitment}

These strategic documents affect the way that recruiting within the iwi is conducted. This was raised by participants throughout the interviews and is discussed in the following section.

It has been argued in the literature that recruitment is pivotal to the success of an organisation's strategy. It is important that the organisation hires people that align with their strategy and who are willing to embody the values of the organisation (Compton, Morrisey, \& Nankervis, 2001). The selection of hiring methods that are consistent with their strategy is also crucial.

When asked about the way the iwi entity recruits, the participants noted the use of informal and formal recruitment systems. The iwi's formal recruitment systems include advertising methods, interviews, processes, and system-based recruitment. The informal recruitment systems include known networks, and approaching candidates directly to work at the organisation.

Hiring is conducted within the organisation mainly through formal recruitment processes unless there is a whānau tie to the iwi entity. As examples, two of the participants I interviewed were given jobs at the iwi due to whānau ties, and had always worked there, for their entire career. The remaining participants secured their roles through advertisements and the formal application process. 
Despite planning for the future however, it is important to acknowledge there is a lack of Ngāi Tahu members recruited with adequate knowledge and experience to fill certain roles. The iwi is currently attempting to fill these roles with the best people who have the right education and experience for the roles. It is tough to find a 'best-fit' candidate, with participants noting that best fit would be someone who had tertiary education and experience, but who is also Ngāi Tahu.

The other way that candidates are recruited is through informal mechanisms and indirect recruitment pathways. For instance, one participant's experiences of how they applied for the job was interesting. This participant was recruited as a result of attending the Aoraki Outward Bound course run by the iwi:

"I was away on the outward bound course, that Ngāi Tahu runs and my old employer was a sponsor of, while I was away and after I had learnt about the Iwi at the course the job came up, I had 24 hours to apply for the job and got it and that was 4 years ago". (CIO, NTH)

This particular participant was attracted to the role because of the values that had been communicated to him about the iwi whilst on the Outward Bound course. He resonated with these values and they were what he was seeking in an organisation. Therefore, the outward perception of the iwi was why the participant was attracted and eventually employed:

"So I've just gone from there, I've been on my hapū boards ever since, was elected to Te Rünanga O Ngāi Tahu in 2002 as a representative” (Deputy Kaiwhakahaere, TRONT)

One of the current issues facing Ngāi Tahu in the recruitment sphere is the lack of qualified and adequately-skilled Ngāi Tahu people coming through to work at the organisation. The current demographic of staff is 50 percent Māori, with 35 percent of that being Ngāi Tahu, and the remaining 50 percent identifying as non-Māori. The quote below highlights this as being one of the key strategic focus areas for the iwi: 
"Restructuring, realigning the organisation to align better with strategy and one of the big kaupapa is we have to have a strategy around our recruitment and be more strategic in our recruitment." (GM, NTH)

When referring to strategy in the above quote, the participant was describing having a more methodical and planned approach to recruitment. This desired approach would link with the inter-generational nature of the organization, including strategies like starting training and career path planning much earlier with rangatahi (young people). This would ensure rangatahi are coming through with the appropriate skills. The strategy also refers to Ngāi Tahu considering recruitment pools with more diversity and approaching suitable candidates rather than relying on candidates approaching them.

The objective is that there are more people from Ngāi Tahu coming through to work and govern the iwi. To achieve this, Ngāi Tahu is looking at the long-term inter-generational effect and, as a part of that, implementing recruitment systems, policies, procedures and building capacity to ensure this can happen:

"So not so much reactive for today, but ensuring we're building that capacity for the future. We're long-term, inter-generational, we've got to have that focus on building capacity and building tribal capacity. So we're rolling out a number of tribal programmes too, for example, one of the goals that we've just set on our commercial boards is that 50\% of those boards must be of Ngāi Tahu descent by 2020." (Deputy Kaiwhakahaere, TRONT).

In addition, Ngāi Tahu have established formalised recruitment systems to ensure there are more qualified Ngāi Tahu members being recruited who can work at the iwi. An example of this is that, there is a succession planning system already in place, as mentioned in the Ngāi Tahu 2025 plan:

"To increase management skills, a mentoring programme is in place that secures succession planning within Te Rūnanga o Ngāi Tahu." (Page 38, Ngai Tahu 2025 Plan)

As one participant noted: 
"For example we have just launched the iwi capability strategy to try to get more Ngāi Tahu into commercial New Zealand and in particular into our business”. (CEO, NTH)

For the meantime, until NTH can find an adequate number of Ngāi Tahu coming through the recruitment process, a key strategic task for the iwi is to define the type of candidate they are looking for today. By this, an ideal candidate would be defined as someone who identifies as Ngāi Tahu and has the skills required for the job. As this is not available at the moment, the iwi must determine what they would seek in a best-fit candidate for the current time.

When asked how they currently define a best-fit candidate for the organisation, the response typically is that it is someone with the adequate skills, experience, and education and if not Ngāi Tahu, then someone who fits within the values of the organisation, as noted in the following quote:

“We look for people that we believe will fit our values”. (HR Manager, NTH)

As mentioned above, NTH is currently looking for candidates who are willing to learn how to align with the values and kaupapa, adhere to them, and respect them in their work.

For new recruits and current employees, there is still an expectation from the iwi to use these values in the way they work every day and to use them to make informed decisions. To ensure this happens, there needs to be adequate training and induction for them to make sure these values are communicated and employees know how and when to use them. The next section will address what training and induction processes Ngāi Tahu has in place currently.

\section{Induction and socialisation}

This section looks at the induction processes that take place within the organisation. As mentioned in the literature review, induction is an important part of the socialisation 
process of new employees. Through the induction process members of the organisation learn about the social norms within the organisation and what is expected of them.

In the case of this iwi entity, one of the key strategies of socialisation is through the sharing of knowledge of the Ngāi Tahu history. A participant mentioned that one of the first things that happens when a new recruit is inducted into the organisation is that they are taught the history of Ngāi Tahu - about the tribe and about the settlement of the entity. This is something that all employees (including my interview participants) go through when they start their work at NTH. Throughout the induction and training process, there are two themes that emerged in the interviews: the formalised way of inducting and training, through policies and procedures; and a more informal induction process that naturally takes place.

Subsequent to this these induction procedures, new recruits are taught why these values are important in a person. They are then reinforced in a tangible sense through a Letter of Expectation, mirroring the practice of presenting a Letter of Expectation to Te Rūnanga:

"We give a Letter of Expectation that says what we expect of you, it will ensure you adhere and abide by the tribal values". (Deputy Kaiwhakahaere, TRONT)

The point to be made about this letter is that Ngāi Tahu noted they are trying to move past values being something that is only talked about or "given lip service to" as one participant mentioned. The idea of the letter is that it is a formal document for the individual to know what they are expected to do to act and abide by the tribal values. It is being implemented as a formal way of socialisation for a newly recruited employee to ensure that kaupapa and values are effectively communicated and adhered to.

To ensure that the value of manaakitanga is upheld, a participant explained that they ensure they welcome new employees as though the organisation is their new home:

"When we first employ staff they have a mihi whakatau... That happens for all staff”. (Deputy Kaiwhakahaere, TRONT) 
A mihi whakatau is a speech (or set of speeches) of greeting made during an official welcome, to acknowledge those gathered together for a particular purpose. The mihi whakatau is an example of how kaupapa is upheld early in the new employee's experience.

In belonging to an organisation, it is important to feel a connection with the organisation. The iwi particularly wants others to feel like it is also their own home. As mentioned above, all of the programmes and training at the iwi always try to incorporate the values and kaupapa of the organisation.

\section{"All of our programmes and training have a common theme around growing and understanding your connection to Ngāi Tahu”. (HR Manager, NTH)}

All training programmes have the intention to be always growing and adaptable. This is evident from the quote above in that the connection to the values and Ngāi Tahu throughout the work of the employees is a central focus.

\section{Informal Mechanisms}

Informal mechanisms are those through which people learn about the environment or social norms at the organisation, through socialisation rather than through formal methods such as documents. Although the participants noted that the organisation may be too light on the formal procedures, there seems to be a great deal of informal socialisation that takes place to support induction and training of new employees.

The quote below describes how, although there were formal activities as part of his induction to the organisation, this participant experienced and learned from social norms and protocol informally:

“There's some more physical things you know, saying your mihi, pronunciation, karakia and going onto the marae, but the protocol, I never got any formal induction or training with that. It was something I informally learned" (CIO, NTH). 
In this quote, when the participant discusses protocol they are talking about the tikanga on the marae. Tikanga refers to marae protocol, including the way you act on the marae, how you behave, and how you respect tapu. This includes activities such as being welcomed onto the marae appropriately, where you sit, and removal of shoes before you enter the marae.

There is also the perception that the iwi provides support to learn these social norms and therefore the socialisation process happens naturally for a lot of the participants. Some of the participants noted that due to the fact that they had grown up in the iwi, the way that the organisation operated was a way of life for them.

Many of the participants however, had to learn these on the job. It can be noted that the learning process of socialisation at the iwi is supported through an open and friendly environment:

"So there is those kind of things you do need induction and help people with and the iwi provide that and it's quite supportive as you learn it". (CIO, NTH)

Many of the participants reflected similar sentiment to that expressed in this quote. They felt they were welcomed into the iwi and that it was an environment where they could learn about how to implement values as others did, in their day-to-day business. Being in a supportive, caring environment is beneficial to the iwi when hiring non-Ngāi Tahu members. Without this, the implementation and preservation of the values would be difficult.

"We can all recite values, and we can put them on posters but if they're not carried in the hearts of people... They are esoteric, they are complex, philosophical deep emotions". (GM, NTH)

This quote demonstrates the importance and significance of informal and formal mechanisms to ensure that these values are ingrained into what people do, that they are understood, and how they work. Therefore, induction and socialisation procedures are paramount to ensuring that the values are carried in the hearts of people that work at Ngāi Tahu. 
From this analysis, it is evident that training and induction occurs in two forms at the organisation. These are formal procedures, such as documents and policies, and informal procedures, such as socialisation into the organisation. Informal mechanisms are based on historical values, and Ngāi Tahu is working to align their formal practices with their informally-managed historical values. The informal mechanism is crucial to the presence of Ngāi Tahu.

\section{Summary}

The thematic analysis highlighted that values emerged within the iwi context to maintain kaupapa Māori. Strategies emerged which are used to maintain these values, through formal mechanisms, policies, and procedures, as well as informal social mechanisms. It was also highlighted that there are challenges in maintaining these values. The next chapter will discuss findings further in relation to the literature. 


\section{Chapter 6 \\ Theoretical Discussion}

This chapter discusses the research findings and relates the emergent themes to the literature. Tikanga Māori and the accompanying values emerged as a significant finding within the analysis. The values of manaakitanga and kaitiakitanga were significant determinants in the way Ngāi Tahu operates strategically. These two values, along with others, formed Ngāi Tahu's kaupapa, or organisational strategy.

\section{Tikanga Māori and Values}

A common theme in the literature on organisational behaviour is the important role that organisational values play for businesses, whether traditional Western businesses or iwi entities. The important difference between values for a Western business and values for an iwi entity is the origin of these values.

The values discussed and implemented at Ngāi Tahu are not driven or designed for commercial success. They are driven by tipuna (ancestors) and respect for te ao Māori. This contrasts Western businesses, where successful adoption of values is seen as necessary only for profit maximisation.

Values are the foundation upon which culture is cemented in an organisation. They are described as perceived understandings by the employees that work at the organisation (Truss \& Grattong, 1994). In the literature they were noted as extremely important for the way the organisation operates and governs itself (Truss \& Grattong, 1994). They are what drive the identity of a firm.

Pettigrew (1979) defines culture to be made up of a collection of fundamental values and belief systems which give meaning to organisations. In the literature about culture, as noted above, we find that the shared assumptions of an organisation play an important role in shaping culture. Similarly, tikanga Māori is the shared assumptions that Māori have and the protocol of the way they operate. Thus, tikanga Māori can manifest as a form of organisational culture. Indeed, my research shows that tikanga Māori is to the iwi entity what organisational culture is to a Western business organisation. 
Along the same lines, traditional Māori values, which are demanded through tikanga Māori, are embedded in the organisation in the same way that values are embedded in a Western organisation. Rokeach (1973) discusses how corporate values can be defined as beliefs that help companies make choices among available means and ends.

This is consistent with literature. Mika and O'Sullivan (2011) propose that in Māori management surround the idea that customs (tikanga) and values are used as a means to create ethical behaviour and hold the organization accountable to whānau, hapū, and iwi. Furthermore, also note that these control characteristics are an attempt to retain culture. The key driver of distinct Māori management systems is Māori attempting to retain assets and cultural identity while still participating in a capitalist system (Mika \& O'Sullivan, 2014).

This point is crucial for this study. Through the findings, a consistent theme that emerged was that Ngāi Tahu use values to hold employees accountable to their kaupapa, to ensure they are making decisions consistent with the kaupapa and vision of the iwi. The kaupapa is established by Ngāi Tahu to ensure that they retain their culture. Values and kaupapa are used as a vehicle to protect tribal ways of operating. What surprised me in this process, was the origins of these values. The fact that they originated from a traditional indigenous culture allow them a much greater level of meaning and richness within the business. The connection and obligation to these values is not a 'ticking-the-box' exercise; it is crucial that the iwi entity acknowledges these values to then acknowledge their ancestors and traditions. This was something that was not acknowledged in the literature about values and where they derived from.

Looking further into the values and how they are expressed in the operational sense, the literature notes that values within an organisation are embedded in the choices made by the business and guide business action (Truss \& Grattong, 1994). This is evident at Ngāi Tahu in the way that values guide decisions and the decision-making process. The values guide the culture of the organisation through specific documentation which is intended to inform and hold people accountable. As noted above, two values were significantly used in the business. The table below provides the definition within the literature and how these values were specifically expressed at Ngāi Tahu. 
Table of Values and their manifestation at Ngāi Tahu

\begin{tabular}{|c|c|}
\hline Value & Operational Manifestation at the Iwi Entity \\
\hline Kaitiakitanga & $\begin{array}{l}\text { A. Documents are used as a strategy to preserve this value } \\
\text { a. 'What is an Investment' Document } \\
\text { b. Letter of expectation } \\
\text { c. Ngāi Tahu } 2025 \text { plan } \\
\text { B. Succession planning in place for future generations }\end{array}$ \\
\hline Manaakitanga & $\begin{array}{l}\text { A. Training on iwi history } \\
\text { B. Informal social uses of the value, through the way people } \\
\text { act in the organisation } \\
\text { C. Communicated in Ngāi Tahu } 2025 \text { plan documents } \\
\text { D. Documents are used as a strategy to preserve this value } \\
\text { a. 'What is an Investment' Document } \\
\text { b. Letter of expectation } \\
\text { c. Ngāi Tahu } 2025 \text { plan }\end{array}$ \\
\hline
\end{tabular}

There are also significant implications of the use of these values as mentioned in the literature. Kuntz et al. (2014) note the following about these values.

Manaakitanga

It is plausible that New Zealand organisations that extend appropriate hospitality by embellishing expressions of cultural identity ensure staff retention and be reciprocated with positive staff behaviours.

\section{Kaitiakitanga}

It is important for organisations employing Māori staff to act in accordance with this value, by, for example, taking the environment into consideration when planning operations, and using natural resources when making decisions. These measures are likely to elicit positive attitudes among Māori and prompt positive social behaviours in the workplace. This was particularly evident in my study, as kaitiakitanga is one of the values Ngāi Tahu use as one their guiding values. It has significant implications on the way they govern and make decisions.

\section{Recruitment}

There are two main discussion points that exist when looking at the current case study and the literature on recruitment in western business. 
Firstly, Ngāi Tahu are considering their needs 10-15 years into the future with their recruitment planning. They currently do not have enough skilled Ngāi Tahu members able to work in the organisation. Their succession plan is aimed towards the next generation and even the generation after that. They have robust succession plans in place, from primary schools through to tertiary education, so that the iwi entity can equip themselves with the best workers possible. Much of the Western business literature on recruitment discusses recruitment being able to find the right employee for right now, with discussions of succession planning very rarely referring to plans more than five years hence. This long-term versus short-term orientation is a significant difference between Ngāi Tahu and the majority of organisations described within the dominant Western literature.

\section{Induction and socialisation}

There is also a significant difference between the way Ngāi Tahu Holdings operates induction and training and the way it is done by most organisations described in the mainstream literature. Ultimately, this difference comes down to the form of the motivation for induction and employment. In much of the literature, training and induction are designed to better equip the worker with skills that are specific to the tasks they perform in their role (Ekhsan and Othman, 2009). By contrast, training and induction occur within Ngāi Tahu because the iwi wants to inform new employees and staff about themselves, in order to maintain and uphold the identity of Ngāi Tahu. The training and induction programmes are not related to upskilling, but focus on tribal history, oral history, tikanga Māori, te ao Māori, and te reo Māori.

Most of the Western literature posits that optimal training comes from planned and systematic activities designed to promote the acquisition of knowledge, focusing on the formalness of the training (Ekhsan and Othman, 2009). This is another area where the iwi entity differed from the literature - although there were formalised programs in place at Ngāi Tahu, the preferred method of training is through informal methods. This reflects the nature of the organisation. In using their value of whanaungatanga, informal methods suit their kaupapa. 
It seems the definition that the process of familiarising new employees with whatever is necessary for them to feel at home and to understand and perform their duties efficiently (Mulders et al., 2010) is more synonymous with the use of manaakitanga of welcoming newcomers into the organisation. This is also noted by Kuntz et al. (2014) who note that organisations that enact this value have a higher chance of retaining employees. This value enables staff to express cultural identity, and is usually reciprocated with pro-social behaviour.

\section{Gaps in the Literature}

Throughout the literature review there were comparisons that could be made between what had previously been written and what emerged at Ngāi Tahu.

\section{$\underline{\text { Traditional Values used as Organisational Values }}$}

The first gap relates to the nature of the firm as a tribal entity. As mentioned above, values form a significant part of the way the iwi operates, and as such as at the centre of this study. The development of values in a classic Western organisation sense is to create values that are consistent with product or brand image, and ultimately serve the purpose of maximising profit.

This differs for many iwi entities. For example, Ngāi Tahu use manaakitanga as one of their main organisational values. This value derives from when the tribe was founded and was used due to the nature of where they were. Tribal members often had to travel large distances to trade and to visit other hapū and members of their whānau. This value was important to the iwi in tribal times and we now see this being translated into an organisational value.

The values used at Ngāi Tahu, are not to affect the bottom line or to gain profit. They are used and communicated throughout the organisation to preserve their identity as an iwi to ensure that manaakitanga is not lost, even through and within commercial environments. This value is something that was central to the tribe when they first formed and now hundreds of years later is a crucial part of how they operate their businesses.

This is just one example of the values which emerged. This gap was found during the interview process. I asked questions of the participants relating to the values they used 
growing up and how they felt this transferred into their working lives today. It was noted that those who grew up with the iwi were taught this from a young age. and it has carried through. By honouring traditional values, iwi entities are giving acknowledgement to tîpuna (ancestors) from the iwi.

The significant point about this is how the value has been translated from the traditional context into the organisational context. This has been done through looking at how their ancestors worked, and then developing this through strategic processes into an organisational context.

\section{$\underline{\text { Western Business Models in Māori Organisations }}$}

One of the key findings and recommendations looks at the strategies implemented by iwi entities to preserve their culture and identity. This is where we start to see a hybrid emerge between Māori/iwi business and Western business models.

Throughout the study, strategies used to preserve culture derive from SHRM practices within Western business models. This is through the formal process of documentation, recruitment, training, and induction models which we see being used in the organisation.

One of the participants noted that diagnosing what is useful from pākehā models and what is not, is one of the hardest parts for the iwi. They are looking to design best-fit models for themselves in this environment. These models may be a mix between Western business models and traditional Māori methods, but it is not always clear how these models should be optimally combined.

\section{Integration of Kaupapa Māori as Strategy}

Perhaps the most significant finding I identified in my original research is the use of kaupapa Māori as a way to form strategy in the iwi. Kaupapa Māori can be defined as any particular plan of action created by Māori, expressing Māori aspirations, and expressing certain Māori values and principles. There might be a range of purposes for the action taken, however it is generally held that the design of the proposed action is created by Māori reflecting Māori aspirations, ideals, values and perspectives. It also incorporates tikanga Māori, distinctive Māori ways of doing things, and cultural behaviours through which kaupapa Māori are expressed and made tangible. 
Though this topic has been discussed previously in Māori history and traditional literature, existing research often refers to traditional methods and to work ethic. The concept of kaupapa Māori emerge as a strategy. This is evident through the use of values and is consistent with the definition above when it notes that it is a plan carried out for the expression of certain Māori values.

Ngāi Tahu have used this kaupapa Māori framework to develop their 25-year strategy. This is evident in the documents analysis when it shows that values are used to form business outcomes for the iwi entity.

\section{Summary}

The findings from this case study are consistent with the literature. However, there are a number of key findings in this study that have not been identified or documented previously in the literature. A strategic framework has been proposed, outlining a strategy to protect kaupapa Māori at Ngāi Tahu in the face of Western business demands.

The next chapter concludes this study, by summarising the key findings in relation to the research question, sub-questions, and research objectives. It will discuss my reflections on the current study and from this, propose future research in this area. Lastly, it will finish by addressing the contribution of this study to the literature. 


\section{Chapter 7 \\ Conclusion and Recommendations}

This chapter will provide an overview of several key elements of the study. Firstly, it will review the research questions and what has been achieved in regard to the research objectives. Secondly, I will reflect on what I have learned from the study. Thirdly, I provide recommendations for iwi entities and Māori business. Finally, I discuss my academic contribution and the contribution of this study generally.

\section{Review of the Research Question}

As mentioned in previous chapters, my study explored the research question: How does an iwi entity preserve their kaupapa Māori (integrity to traditional values) through their mahi (work) whilst operating in a western business context? The questions were examined using in-depth interviews with participants, supported by a document analysis of key strategic and operational organisational documents.

The most essential underlying theme in this current study was the embedded and significant use of traditional Māori values in the way the business operates. The study revealed that values are prevalent in all operations, from everyday decision making to high-level strategic goals and documents. To use the traditional values is to preserve the culture of the iwi through organisational operations. It was found that the two values most widely practiced, manaakitanga and kaitiakitanga, were traditional values that were developed when the iwi was first created. By developing the values in operations and adhering to them in actions, the iwi entity and its participants preserve the culture of Ngāi Tahu.

Preserving these values presented conflict for the iwi entity. It affects the way they make decisions and with that brings conflict. It was noted that this was particularly evident in the trade-off between commercial outcomes (profit) and social outcomes (such as improve well-being for iwi members). The nature of this conflict affects the perception of the iwi as a business from an investment point of view and from an external point of view. 
In preserving these values, there are practices within the iwi that have been implemented. This implementation has been through formal and informal mechanisms.

Formally, the iwi has implemented key documents which hold employees accountable for adhering to the values. The documents share the iwi's expectation of the different business arms in the way they are expected to use these values to guide them in making decisions relating to investment and strategic direction. The over-arching strategic document uses specific values to guide the direction of the organization.

There are also specific formal programmes put into place by the organisation through their recruitment, training, and induction processes that ensure their kaupapa is maintained. In their recruitment phase, there is significant succession planning which occurs, feeding into their value of using kaitiakitanga and upskilling the iwi for the future. Then through the induction and training processes, there are programmes in place to help newcomers learn about the values and how they are used within the organisation, so they are knowledgeable of the kaupapa of the organisation.

Informally, socialisation within the organisation was a key aspect of the way training occurred at the entity. People were taught about protocol and the values were communicated through day-to-day informal conversation and activities which allowed them to learn about the way values were used within the organisation.

These findings show that I have achieved the research objectives that I began with. The first objective was to understand what processes are put in place through recruitment, training, and induction processes to protect kaupapa Māori in the organisation. The study identified that there are formal and informal procedures in place throughout the recruitment, training, and induction phase at the iwi and these are used to protect the kaupapa in the organisation.

The second objective was to identify how the organisation defined their best-fit candidate. I learned through the process that a best-fit candidate is subject to place and time. Ngāi Tahu is aiming to increase and continue to grow the number of employees identifying as being of Ngāi Tahu descent in the organisation. However, they do not currently have enough skilled Ngāi Tahu employees progressing through the organisation. For now, a 
best-fit candidate is someone who fits in with the values at Ngāi Tahu. In the future, bestfit will be someone who identifies as Ngāi Tahu.

The third objective was to find out what challenges lie ahead for iwi entity. I think the main challenge still exists within the research question. The main challenge is ensuring that kaupapa Māori is always maintained and adhered to in the way that businesses operate. It was noted that tighter policies and controls have to be implemented as the different arms of the business grow further away from the centre of the business and so are not as easily held accountable when they make choices that are not consistent with the organisation's kaupapa.

\section{My Reflections on the Study}

I have four major reflections about the findings of the current research. The first reflection is that as this was a case study analysis, the findings are limited to this iwi entity. Its location, history, and stories make the organisation extremely unique. Therefore, it should be understood that the data and findings from the organisational documents may not always apply to other iwi entities or in the same way.

My second reflection is similar to the first. The participants I interviewed are employees of Te Rūnanga o Ngāi Tahu, and Ngāi Tahu holdings. Their opinions, experiences and perceptions are not representative of the entire iwi organisation, nor are they reflective of the iwi itself.

My third reflection is that if I had more time I would have liked to interview participants from across the other arms of the iwi and organisation to ensure I achieved a well-rounded data collection. I believe this would have brought in greater insight to my data.

My last reflection is that I would have liked to have added observation into my data collection tools. After I visited Ngāi Tahu and was immersed in the culture and conducted the interviews, I realised that it is a highly complex business environment. I would have liked to have been able to spend more time shadowing some of the participants to gain a greater understanding of how kaupapa is embodied on a day-to-day basis. I feel this would have given me greater insight at a deeper level - perhaps embedded engagement would provide richer understanding of kaupapa Māori research methods. 
These reflections largely have to do with the time constraints of this thesis and provide a platform as to what further research could be conducted in order to generate insight for other iwi entities.

\section{Recommendations for Future Research}

As mentioned in chapter one, the Government is aiming to conclude historic Treaty settlements by the end of 2016. This will mean a significant amount of iwi and hapu looking to form business entities as they receive financial reparation for past grievances. It is a crucial area of the economy which is about to grow and also an area which I feel is significantly overlooked in research and overlooked when we think about the way we discuss Māori business and the Māori economy itself.

My research is the first type of academic research which examines the inner workings of an iwi entity and but provides only a slice of analysis. This study should be the first of many to analyse these complex organisations. From a management and SHRM perspective, iwi entities are an interesting environment to study and observe. From my experience, they act as a profit maximising firm, a not-for-profit organisation, a family business, and a start-up company all-in-one.

There is a danger in assuming all Māori organisations or iwi entities are alike. Therefore, my first recommendation for future study is to look at doing a comparative study of two different iwi, comparing the different ways in which they maintain kaupapa Māori. As previously mentioned, my study was a case study that looked solely at Ngāi Tahu. Due to iwi being so unique in nature I think this would be important to further develop the idea of kaupapa Māori as a strategic approach.

My second recommendation for future research is to explore the idea of the quadruple bottom line reporting system. This was a point discussed by some of the participants as a way that iwi entities could measure the culture element within the organisation in the future. As a research topic, this would generate useful insight for the Iwi organisations.

Thirdly, I recommend more in depth research on succession planning in Māori entities such as Ngāi Tahu. One of the issues that arose seemed to be that there weren't enough 
skilled workers coming through into the organisations that identified as being of Ngāi Tahu descent. I believe it would be valuable to look in more detail at the succession planning in place, particularly aimed at tertiary students rather than my study focused on the adult working pool from which they recruited.

My final recommendation is for further research which directly contrasts an iwi entity to a western organisation, in order to better see how frameworks from family business literature, not-for-profit organisations and start-up organisations fit within an iwi context and vice versa.

For the benefit of researchers who would like to conduct a study in this field, there are considerations which must be taken into account. There is significant importance in being knowledgeable and respecting tikanga Māori. If you cannot do this, you will not be able to fully immerse yourself in the research and also understand the importance at an intrinsic level the people's experiences and what they mean. One of the key ways Māori culture and myth has survived is through oral tradition and storytelling. Therefore, it is important to listen to the stories people have to tell.

Following the kaupapa Māori research approach and designing research strategies conducive with this is important. Whether it be a qualitative or quantitative study, research must be conducted in an appropriate cultural way as to not be disingenuous or disrespect the mana of te ao Māori.

\section{The Contribution of my Research}

The key research findings contribute to the field of HRM and management in three key ways.

The first contribution is that this is the first study of this kind. There has been no study on iwi entities or Māori organisations and looking at how SHRM and management theory is presented in this business context. The study provides an in-depth understanding that their strategic direction, recruitment, training, and induction processes are culturally driven. They are not driven only to improve the bottom line of the business, but are driven by a need to protect Māori culture throughout Western business contexts. 
The second contribution of this study relates to the use of values and training processes as a way to maintain cultural identity. It was noted in the literature that this is mainly used to up-skill workers to improve the bottom line of a business. In the case of iwi entities, they can be used to preserve values.

The third contribution relates to the practical implications for iwi entities operating in a Western business context. Participants' experiences and perceptions regarding the challenges indicated that there are more road-blocks ahead for these types of entities. This contribution can act as a reference point for these organisations and can also act as a beacon for more organisations and researchers to focus on this area of Māori economy as an emerging and important area of business.

Overall, this study fills a significant gap in the literature and from a practical perspective in Māori business, management, and HRM. But there is a need for further research in this area . The findings have generated insight for considerations of management and HRM but must not be generalised as a homogenous way for Iwi to act or operate.

I, as a passionate participant in the research process acknowledge that my findings may be biased towards the positive use of Māori values in business. It is however, apparent from the findings that they are significant in the way kaupapa Māori is protected in iwi entities. We as a society can never dismiss te ao Māori and the part it has to play in the way business operates and has always operated for Māori.

To conclude the thesis, I would like to end it with a proverb so that we always remember those who came before us and created the foundation we now have for studies like this and to remember why we treasure our culture as taonga:

Kia mau koe ki ngā kupu o ou tīpuna - Hold fast to the words of our ancestors. 


\section{Reference List}

Ashforth, B. E. (1985). Climate Formation: Issues and Extensions. Academy of Management Review, 10(4), 837-847.

Barcham, M. (1998). The Challenge of Urban Māori: Reconciling Conceptions of Indigeneity and Social Change. Asia Pacific Viewpoint, 39(3), 304-314.

Bargh, M. (2012). The Post-Settlement World (So Far): Impacts for Māori. In N. R. Wheen, \& J. Hayward (Eds.), Treaty of Waitangi Settlements. Wellington, New Zealand:Bridget Williams Press.

Breaugh, J. A. (1981). Relationships between recruiting sources and employee performance, absenteeism, and work attitudes. Academy of Management Journal, 24(1), 142-147

Belgrave, M. (2012). Negotiations and Settlements. In N. R. Wheen. \& J. Hayward (Eds.), Treaty of Waitangi Settlements. Wellington, New Zealand: Bridget Williams Press.

Best, P \& Love, M. (2010). Māori values for Māori business: Cultural Capital in Indigenous Organisations. Victoria University working paper series.

Blau, P. M. (1964). Exchange and power in social life. Transaction Publishers.

Brougham, D., Haar, J., \& Roche, M. (2015). Work-family enrichment, collectivism, and workplace cultural outcomes: a study of New Zealand Māori. New Zealand Journal of Employment Relations (Online), 40(1), 19.

Chen, M. (2012). Post-Settlement Implications for Māori-Crown Relations. In N. R. Wheen. \& J. Hayward (Eds.), Treaty of Waitangi Settlements. Wellington, New Zealand: Bridget Williams Press. 
Chen, M. (2015). The Impacts of Post-Treaty Settlement Super Diversity on New Zealand for 2040. Superdiversity Stocktake: Implications for Business, Government and New Zealand (2015).

Compton, R. L., Morrissey, W. J., Nankervis, A. R., \& Morrissey, B. (2009). Effective recruitment and selection practices. $\mathrm{CCH}$ Australia Limited.

Cowie, D. (2012). The Treaty Settlement Process. In N. R. Wheen, \&. J. Hayward (Eds.), Treaty of Waitangi Settlements. Wellington, New Zealand: Bridget Williams Press.

New Zealand History. (2015). Chief Justice declares Treaty 'worthless' and a 'simple nullity'. Retrieved from http://www.nzhistory.net.nz. Retrived on: 12/11/2015

Durai, P. (2010). Human Resource Management. New Delhi: Dorling Kindersley.

Durie, M. (2001). Mauri Ora: The dynamics of Māori Health. Auckland: Auckland University Press.

Ekhsan Abang Othman, A. (2009). Strategic integration of human resource management practices: Perspectives of two major Japanese electrical and electronics companies in Malaysia. Cross Cultural Management: An International Journal, 16(2), 197-214.

Garavan, T. N. (2007). A strategic perspective on human resource development. Advances in Developing Human Resources, 9(1), 11-30.

Glynn, T. (2008). Engaging and working with Māori? Effective practice for psychologists in education. The Bulletin, 110, 22-29.

Haar, J., \& Delaney, B. (2009). Entrepreneurship and Māori cultural values: using'whanaungatanga'to understanding Māori business. New Zealand Journal of Applied Business Research, 7(1), 25. 
Haar, JM., \& Brougham, DM. Support for Māori culture in the workplace: A social exchange theory approach.

Haar, JM., Roche, M., \& Taylor, D. (2012). Work-family conflict and turnover intentions of indigenous employees: the importance of the whānau/family for Māori. International Journal of Human Resource Management. 23(12), 2546-2560.

Haar, JM., \& Brougham, D. (2011). Consequences of cultural satisfaction at work: A study of New Zealand Māori. Asia Pacific Journal of Human Resources. 49(4), $461-475$

Hayward, J. Wheen. N. R. (2012). The Meaning of Treaty Settlements and the Evolution of the Treaty Settlement Process. In N. R. Wheen \& J. Hayward (Eds.), Treaty of Waitangi Settlements Wellington, New Zealand: Bridget Williams Press.

Harmsworth, G., Barclay-Kerr, K., \& Reedy, T. M. (2002). Māori sustainable development in the 21st century: The importance of Māori values, strategic planning and information systems. He Puna Korero: Journal of Māori and Pacific Development, 3(2), 40.

Henry, E., \& Pene, H. (2001). Kaupapa Māori: locating indigenous ontology. 8(2), 234242.

Hill, R., \& Stewart, J. (2000). Human resource development in small organizations. Journal of European industrial training, 24(2/3/4), 105-117.

Jahnke, H. and J. Taiapa (2003) "Māori research" in C. Davidson and M. Tolich (eds.) Social Science Research in New Zealand: Many Paths to Understanding, Pearson, Auckland.

Joseph, R. (2012). Unsettling Treaty Settlements. In N. R. Wheen. \& J. Hayward (Eds.), Treaty of Waitangi Settlements. Wellington New Zealand: Bridget Williams Press. 
Katene, S. (2010). Modelling Māori leadership: What makes for good leadership. Mai Review, 2, 1-16.

Kawharu, M. (2000). Kaitiakitanga: a Māori anthropological perspective of the Māori socio-environmental ethic of resource management. The Journal of the Polynesian Society, 349-370.

Kuntz, J. R., Näswall, K., Beckingsale, A., \& Macfarlane, A. H. (2014). Capitalising on Diversity. Journal of Corporate Citizenship, (55).

Post Treaty Settlements. (2015). Imagining a Post-Settlement Future: In this Together? . Retrieved from http://posttreatysettlements.org.nz/imagining-a-post-settlementfuture-in-this-together/ 10/10/2015

Love, P. B. M. (2010). Māori Values for Māori Business: Cultural Capital in Indigenious Organisations Working Paper Series Victoria Univeristy of Wellington Victoria Business School

Marler, J. H. (2012). Strategic Human Resource Management in Context: a Historical and Global Perspective. The Academy of Management Perspectives, 26(2), 6-11.

Millmore, M. (2003). Just how extensive is the practice of strategic recruitment and selection? Irish Journal of Management, 24(1), 87.

Mika, J. P., \& O'Sullivan, J. G. (2014). A Māori approach to management: Contrasting traditional and modern Māori management practices in Aotearoa New Zealand. Journal of Management \& Organization, 20(05), 648-670.

Mutu, M. (2012). Unsettling Treaty Settlements. In N. R. Wheen. \& J. Hayward (Eds.), Treaty of Waitangi Settlements. Wellington, New Zealand: Bridget Williams Press.

Ngāi Tahu (2000). Ngāi Tahu 2025 plan 
O'Regan, S. T. (2014). The Economics of Indigenious Survival and the Development of Culturally Relevant Governance Address.

O'Leary, Z. (2004). The essential guide to doing research. Sage.

Pettigrew, A. M. (1979). On studying organizational cultures. Administrative Science Quarterly, 570-581.

Potaka, T. W. (2010). Legislation and Legislature. In M. Mulholland.\& V. Tahwai (Eds.), Weeping Waters: The Treaty of Waitangi and Constitutional Change (pp. 83-108). Wellington, New Zealand: Huia Publishers.

Rangiheuea, T. (2010). Urban Māori In M. Mulholland. a. V. Tawhai (Eds.), Weeping Waters: The Treaty of Waitangi and Constitutional Change (pp. 187-206). Wellington, New Zealand: Huia Publishers.

Ramamoorthy, N., \& Carroll, S. J. (1998). Individualism/collectivism orientations and reactions toward alternative human resource management practices. Human relations, 51(5), 571-588.

Richards, V. K. A. C. (2014). Lessons from resource management by indigenious Māori in New Zealand: Governing the ecosystems as a common. Econological Economics, (102), 1-7.

Roche, M., Haar, JM., \& Brougham, DM. (2014). Māori leaders' well-being: A selfdetermination perspective. Paper presented at the Australia and New Zealand Academy of Management

Roberts, M., Norman, W., Minhinnick, N., Wihongi, D., \& Kirkwood, C. (1995). Kaitiakitanga: Māori perspectives on conservation. Pacific Conservation Biology, 2(1), 7-20.

Rokeach, M. (1973). The nature of human values. (Vol. 438). New York: Free press. 
Ruru, J. (2010). The Waitangi Tribunal In M. Mulholland. \& V. Tahwai (Eds.), Weeping Waters: The Treaty of Waitangi and Constitutional Change. (pp. 127-142). Wellington, New Zealand: Huia Publishers.

Ruwhiu, D., \& Cathro, V. (2014). 'Eyes-wide-shut': Insights from an indigenous research methodology. Emergence: Complexity and Organization, 16(4), G1.

Ruwhiu, D. Whakawhanaungatanga-Culturally Situating The Organisational Researcher. Retrived 12 July, 2016

Salas, E., \& Cannon-Bowers, J. A. (2001). The science of training: A decade of progress. Annual review of psychology, 52(1), 471-499.

Salas, E., Tannenbaum, S. I., Kraiger, K., \& Smith-Jentsch, K. A. (2012). The science of training and development in organizations: What matters in practice. Psychological science in the public interest, 13(2), 74-101.

Settoon, R. P., Bennett, N., \& Liden, R. C. (1996). Social exchange in organizations: Perceived organizational support, leader-member exchange, and employee reciprocity. Journal of applied psychology, 81(3), 219.

Schwimmer, E. (1966). The World of Māori. Wellington: A. H. \& A. W. Reed.

Spiller, C. M. (2010). How Māori cultural tourism businesses create authentic and sustainablewell-being (Doctoral dissertation, ResearchSpace@ Auckland).

Spiller, C. P. E. \& Erkaovic, L. (2011). Wise up: Creating Organisation Wisdom through an ethic of Kaitiakitanga. Journal of Business Ethics, 687-706.

Stake, R. E. (2013). Multiple case study analysis. Guilford Press.

Truss, C., \& Gratton, L. (1994). Strategic human resource management: A conceptual approach. International Journal of Human Resource Management, 5(3), 663-686. 
Warriner, V. (2007). The importance of traditional Māori values for necessity and opportunity: Māori entrepreneurs-iwi-based and individually owned. International handbook of research on indigenous entrepreneurship, 558-564.

Walker, S., Eketone, A., \& Gibbs, A. (2006). An exploration of kaupapa Māori research, its principles, processes and applications. International Journal of Social Research Methodology, 9(4), 331-344.

Wright, P. M., \& McMahan, G. C. (2011). Exploring human capital: putting 'human' back into strategic human resource management. Human Resource Management Journal, 21(2), 93-1 


\section{Appendices}

Appendix A - Interview Schedule A

\section{Interview Schedule for HEC Application \\ (Organisation leader and senior managers) \\ Iwi in the Post-Settlement World}

Description of Interview: This study is designed to examine the challenges faced by Iwi enterprise in the western business context and to provide a case study which

$\mathrm{h}$ generates insight regarding how these challenges can be met. Victoria University requires, and has granted, approval from the School's Human Ethics Committee. This interview will be digitally recorded and will adhere to all agreed points in the information sheet and consent form. You will not be identified in the transcription of this interview or through the use of quotations from this unless you give permission. A transcript of the interview will be provided to you and at the conclusion of the research I will also present a seminar on the findings to you. As agreed in the consent form you are free to withdraw from participating in this study at any up until 30 January 2016.

\section{Background}

1. Before we talk about [Case study organisation] and your work here and I am interested in your broader background:

- Do you identify as [Name of Iwi]?

- Where did you grow up?

- Did you have much involvement with Iwi community/activities as you grew up?

- What values were taught to you as you grew up?

- What would you describe is the kaupapa and tikanga of the Iwi (if from case organisation Iwi)?

2. What is your education background?

3. What previous work have you done?

\section{Organisational context}

1. Could you please describe your firm and the market that [Case study organisation] operates in?

2. In your experience here at [Case study organisation] what are some of the challenges you think the iwi entity faces in operating in a commercial environment?

- Examples of this

3. Are the challenges different to those of other organisations you've worked at? 
Appendices

\section{Organisational role}

4. How did you come to be working at [Case study organisation]?

5. What is your role here at [Case study organisation]?

- What sorts of activities do you do?

- What skills/ experience do you need for your role?

4. How did you get your job here?

- Was it formally advertised?

- What were the processes of recruitment?

- What did you know about the organisation before you thought about working here?

- Any apprehensions about coming into an Iwi environment

5. How long have you been here at [Case study organisation]?

6. How is your current role different to their previous roles in respect to it being an Iwibased enterprise?

\section{Kaupapa and Tikanga of [Case study organisation]}

7. How would you describe the kaupapa and tikanga of [Case study organisation]?

- Does this align with the kaupapa and tikanga of [Iwi]?

- Perhaps a question here about the role of kaumātua in leading their and their organisation's work

8. When you began here, how did you learn about the tikanga and kaupapa of the organisation?

- Were there any particular events/ activities that you were involved in to welcome you to the organisation?

- Was there any formal discussion of the tikanga and kaupapa with you when you arrived (or documentation provided to you)?

9. What type of training have you received here at [Case study organisation]?

- Have you received any training that was designed to help you maintain the kaupapa and tikanga of the organisation throughout your work?

10. If you have, has this training led you to do anything differently? If so, how?

- Adapt your leadership style?

Important takeaways

11. From your perspective, what challenges exist in adhering to the unique kaupapa of [case study organisation]? 
Appendices

12. From your perspective and using your experience, how important is kaupapa and tikanga to Māori organisations more broadly?

\section{Sum up}

13. What challenges exist for [case study organisation] in terms of aligning with and further progressing the tikanga and kaupapa of [Iwi]?

- From a strategic perspective

- Meeting stakeholder expectation

14. Do you have anything else you would like to add? 
Appendix B - Interview Schedule B

\section{Interview Schedule for HEC Application}

(Human Resource Managers)

\section{Iwi in the Post-Settlement World}

Description of Interview: This study is designed to examine the challenges faced by Iwi enterprise in the western business context and to provide a case study which generates insight regarding how these challenges can be met. Victoria University requires, and has granted, approval from the School's Human Ethics Committee. This interview will be digitally recorded and will adhere to all agreed points in the information sheet and consent form. You will not be identified in the transcription of this interview or through the use of quotations from this unless you give permission. A transcript of the interview will be provided to you. At the conclusion of the research I will also present a seminar on the findings to you. As agreed in the consent form you are free to withdraw from participating in this study at any up until 30 January 2016.

\section{Background}

1. Before we talk about [Case study organisation] and your work here and I am interested in your broader background:

- Do you identify as [Name of Iwi]?

- Where did you grow up?

- Did you have much involvement with Iwi community/activities as you grew up?

- What values were taught to you as you grew up?

- What would you describe is the kaupapa and tikanga of the Iwi (if from case organisation Iwi)?

2. What is your education background?

3. What previous work have you done?

\section{Organisational context}

4. Could you please describe your firm and the market that [Case study organisation] operates in?

5. In your experience here at [Case study organisation] what are some of the challenges you think the iwi entity faces in operating in a commercial environment? 
Appendices

\section{Kaupapa and Tikanga of [Case study organisation]}

6. How would you describe the kaupapa and tikanga of [Case study organisation]?

a. Does this align with the kaupapa and tikanga of [Iwi]?

7. When you began here, how did you learn about the tikanga and kaupapa of the organisation?

b. Were there any particular events/ activities that you were involved in to welcome you to the organisation?

c. Was there any formal discussion of the tikanga and kaupapa with you when you arrived (or documentation provided to you)?

8. What type of training have you received here at [Case study organisation]?

d. Have you received any training that was designed to help you maintain the kaupapa and tikanga of the organisation throughout your work?

e. How has this effected the way you work? Do you implement this in your role?

9. From your perspective, what challenges exist in adhering to the unique kaupapa of [case study organisation]?

\section{Hiring and Recruitment}

10. What challenges are most commonly associated with hiring senior managers and recruiting senior managers for the Iwi?

11. What are the most important aspects that you look for in applicants?

12. Technical knowledge?

13. Is it experience?

14. Where they are from?

15. Māori vs non Māori?

16. What processes do you use to find potential managers and organisation leaders?

17. Different talent pools- what kind?

18. Networking - do you use previous networks? Or are there any created for this process?

19. How do you advertise vacant positions?

20. Do you use informal or formal recruiting methods?

21. Can you provide some examples? What is the usual process of appointing a senior leader into a role?

22. Why do you take the approach that you do? 
23. Is this a different approach from other workplaces you've been at?

\section{Induction}

24. What happens when someone first starts working here?

a. Are there any formal processes of induction in place? If so, what are they?

25. How do ensure that new employees understand the culture here at [Case study organisation]?

26. Are there any special events or activities they are expected to be involved in?

27. Are there any policies relating to the Kaupapa and tikanga of the organisation?

b. Try to discuss whether these incorporate values, tikanga etc.

28. Are there any formal programs?

\section{Training}

29. What sorts of training is available in your organisation?

30. Is there any training relating specifically to Iwi culture and values?

\section{Sum up}

31. What challenges exist for [case study organisation] in terms of aligning with and further progressing the tikanga and kaupapa of [Iwi]?

32. Do you have anything else you would like to add? 


\title{
Participant Consent Form
}

\author{
"Mō tātou, ā, mō kā uri, ā, muri ake nei - for us and our children after us"- Iwi \\ Enterprise in the post settlement world.
}

I have read the project information sheet for this study and have had the details of the study explained to me. My questions about the study have been answered to my satisfaction, and I understand that I may ask further questions at any time. I also understand that I can decline to answer any question in the interview and I am able to withdraw from the study at any time up until 30 January 2016.

I have been provided with adequate information relating to the nature and objectives of this research project, I have understood this information and have been given the opportunity to seek further clarification or explanations, I understand that I will be participating in a (video/audio) recorded interview, I understand that I may withdraw from this study (insert date), and any data that I have provided will be returned to me or destroyed, I understand that the researcher and supervisor will have access to the raw data but my name will be changed beforehand to maintain confidentiality and I will only be identified through the position descriptor I choose. I understand that the results will be used for a Masters report and summary results of this survey may be published in academic or professional journals and/ or presented at professional or academic conferences, but that my name will have been changed, (and no identifiable information that is traceable to me will be included), I understand that when this research is completed, the raw data obtained will be destroyed after five years.

I wish to be identified by the position descriptor:

\section{Participant:}

Signed:

Name:

Date:

I would like a copy of the transcript from this interview

If you would like a copy of the transcript from this interview, please list your preferred contact details below for this to be sent too.

\section{Contact Details \\ Postal Address:}

\section{Email Address:}


Appendix D - Participant Information Sheet

TE WHARE WĀNANGA O TE OPOKO O TE IKA A Mãut

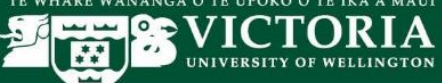

\author{
SCHOOL OF MANAGEMENT \\ TE KURA WHAKAHAERE \\ LEVEL 10, RUTHERFORD HOUSE, PIPITEA CAMPUS, 23 LAMBTON QUAY, WELLINGTON
}

\section{Participant Information Sheet} “Mō tātou, ā, mō kā uri, ā, muri ake nei - for us and our children after us"
1_ Iwi enterprise in the post settlement world.

This study is designed to examine the challenges faced by Iwi enterprise in the western business context and to provide a case study which generates insight regarding how these challenges can be met. The thesis will examine the challenges of retaining and maintaining tikanga(protocol) and kaupapa (work ethic/way of doing things) with a specific focus on the recruitment, induction and training of senior managers entering the organisation, and what policies are implemented to ensure the right person is hired (be it Māori or non-Māori) to carry out the work needed but also to uphold the kaupapa (work ethic/way of doing things) of the Iwi. Victoria University requires, and has granted, approval from the School's Human Ethics Committee.

I am inviting Organisation Leaders, Senior Managers, and Human Resource Managers from [case study organisation] to participate in this research. Participants will be asked to take part in an interview that will take up to 1 hour. Permission will be asked to record the interview, and a transcript of the interview will be sent to participants for checking. At the conclusion of the research you will be invited to a seminar where I will present the findings from this research.

Participation is voluntary. You may withdraw at any time from the interview and the study up until 30 January 2016 and your data collected up to that point will be destroyed. You will not be identified personally in any written publication of the findings without your consent. You will be identified by a chosen pseudonym, which you can select on your consent form. All material collected will be kept securely, and will be viewed only by myself and my supervisor Dr Sarah ProctorThomson. The thesis will be submitted for marking to the School of Management, and subsequently deposited in the University Library. All data collected from participants will be destroyed within 5 years after the completion of the project. The findings from this research may be used for journal publication and/or conference proceedings.

Ngā mihi

Erin Roxburgh

roxburerin@vuw.ac.nz

0272306181
Dr. Sarah Proctor-Thomson sarah.proctor-thomson@vuw.ac.nz

044639982

\footnotetext{
${ }^{1}$ http://Ngāitahu.iwi.nz/Ngāi-tahu/
} 